MAESTRÍA EN BIOLOGÍA EXPERIMENTAL

\title{
T E S I S
}

QUE PARA OBTENER EL GRADO DE:

MAESTRA EN BIOLOGÍA EXPERIMENTAL

$P \quad R \quad E \quad S \quad E \quad N \quad T \quad A$ :

B.E. Erika Contreras Nuñez.

EFECTO DE LA GLICINA

SOBRE LA VÍA DE ACTIVACIÓN DE NFאB Y SU REGULACIÓN EN ADIPOCITOS.

Co-Directores:

Dr. Francisco Javier Alarcón Aguilar

Dr. Miguel Cruz López

Asesor:

Dr. Gerardo Blancas Flores

México D.F., Febrero del 2013 
"El Programa de Maestría en Biología Experimental de la Universidad Autónoma Metropolitana pertenece al Programa Nacional de Posgrados de Calidad (PNPC) del CONACyT, registro 001481, en el Nivel Consolidado, y cuenta con apoyo del mismo Consejo, clave DAFCYT-2003IMPTNNN0020".

El presente trabajo se realizó gracias al apoyo proporcionado por el CONACyT a través de la beca otorgada a la alumna Erika Contreras Nuñez con el Número de Becario: 233171.

El presente trabajo agradece el apoyo proporcionado por el COMECyT a través de la convocatoria Becas de Tesis de posgrado 2011 otorgada a la alumna Erika Contreras Nuñez con el Número de Folio: 12BTM0090. 


\section{MIEMBROS DEL JURADO}

El jurado designado por la Comisión Académica del Posgrado en Biología Experimental de la División de Ciencias Biológicas y de la Salud de la Universidad Autónoma Metropolitana Unidad Iztapalapa, aprobó la tesis titulada “EFECTO DE LA GLICINA SOBRE LA VÍA DE ACTIVACIÓN DE NF-KB Y SU REGULACIÓN EN ADIPOCITOS" que presentó la Lic. en B.E. Erika Contreras Nuñez el día 27 de Febrero del 2013.

Dr. Julio César Almanza Pérez (Presidente)

Profesor titular C

Laboratorio de Farmacología

Dpto. Ciencias de la Salud. D.C.B.S.

Universidad Autónoma Metropolitana - Iztapalapa. icap@xanum.uam.mx

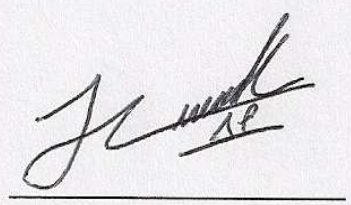

\section{Dra. Rebeca García Macedo (Secretaria)}

Investigador asociado $\mathrm{C}$

Unidad de Investigación Médica en Bioquímica

Hospital de Especialidades CMN SXXI. IMSS

gamareb@yahoo.es

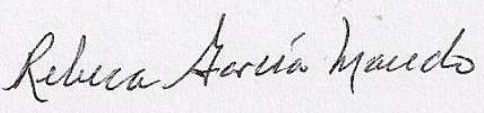

Dr. Gerardo Blancas Flores (Vocal)

Profesor asociado D

Laboratorio de Farmacología

Dpto. Ciencias de la Salud. D.C.B.S.

Universidad Autónoma Metropolitana - Iztapalapa.

gera@xanum.uam.mx

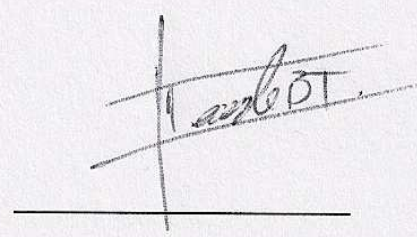

Dr. Fausto Sánchez Muñoz (Vocal)

Investigador en Ciencias Médicas D

Dpto. Inmunología.

Instituto Nacional de Cardiología "Ignacio Chávez" fausto22@yahoo.com

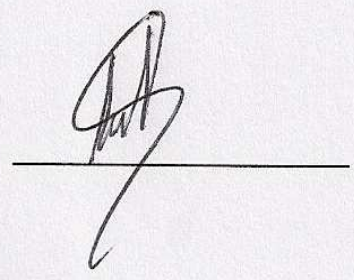




\section{COMITÉ TUTORAL}

\section{Codirectores:}

Dr. Francisco Javier Alarcón Aguilar

Profesor titular C

Laboratorio de Farmacología

Dpto. Ciencias de la Salud. D.C.B.S.

Universidad Autónoma Metropolitana - Iztapalapa.

aaasj2@prodigy.net.mx

\section{Dr. Miguel Cruz López}

Investigador titular B y Jefe de la Unidad.

Unidad de Investigación Médica en Bioquímica

Hospital de Especialidades CMN SXXI. IMSS

mcruzl@yahoo.com

\section{Asesor:}

Dr. Gerardo Blancas Flores

Profesor asociado D

Laboratorio de Farmacología

Dpto. Ciencias de la Salud. D.C.B.S.

Universidad Autónoma Metropolitana - Iztapalapa.

gera@xanum.uam.mx 
A mi Famílía

que siempre me Grindan su Amor, respeto, cariño y apoyo incondicional. 
La realidad de las cosas no está frente a nuestros ojos...

más bien están dentro de estos.

Lo simple de la vida, hace que sea dificil vivir,

y solo las palabras nos ayudan a construir nuestra realidad,

estas no cambian ni se mudan, permacen intrinsicamente aqui,

como una foto cuando el alma está hablando. 


\section{Agradecimientos}

Ha sido un año lleno de esfuerzos y sacrificios, cerrada esta etapa, me queda agradecer principalmente...

$\mathcal{A}$ Dios por íluminar siempre mi camino y permitir el que siga en el.

$\mathcal{A}$ mi bebe Marco Antonio Dolores Contreras por acompañarme en esta etapa tan maravilfosa y estar siempre a mi lado, siendo el motor que me impulsó a seguir adélante a pesar de las adversidades y a pesar de tu edad entender mi ritmo de vída acoplándonos el uno al otro por ser la persona que ha llenado mi corazón de felicidad.

$\mathcal{A}$ mí marido Leonardo Dolores Hernández por su amor y cariño que me ha brindado a lo Cargo de esta etapa en la que me ha apoyado ya sea en los buenos y malos momentos ya que fue capaz de alentarme siempre que algo ífa mal y por ayudarme a trazar este largo camino y Clenarlo de dicha y placer, por estar siempre juntos formando una parte muy importante en mí corazón. 
$\mathcal{A}$ mis padres Marilú $\mathcal{N} u \tilde{n} e z$ Delgado y Humberto Contreras García por impulsarme a seguir adelante con esta carrera que me llena de orgullo y refleja lo que tiene mi corazón.

$\mathcal{A}$ mis hermanos por apoyarme y darme el aliento necesario para superarme y ser una mejor persona.

$\mathcal{A}$ mis amigos Gerardo García, $\mathcal{M}^{a}$ Elizabeth y Malinalli por brindarme su amistad, su confianza y cariño incondicional, por compartir esta etapa tan linda y hermosa llena de conocimientos y virtudes, por estar en las buenas y en las malas siempre juntos apoyándonos el uno al otro porque son especiales para mi, muchas gracias.

$\mathcal{A}$ mis amigos y compañero de Farmacología Gabriela, Jessica, Vladimir, Iván, Humberto, Ana Susunaga, Ana López, Korina, Jose, Cristína por sus consejos, conocimientos, opiniones, crítica constructiva y saber que conté y podre contar con ustedes y con su apoyo, gracias. 
$\mathcal{A}$ l Dr. Gerardo Blancas, Dr. Julio Almanza, Dr. Alarcón, Dr. Cruz, Dr. Zentella, Dr. Carmen por su gran apoyo y motivación para la culminación de este proyecto, ya que son una parte importante en mi formación académica y profesional. 
^ Índice de figuras............................................................................ i

^ Índice de tablas............................................................................... ii

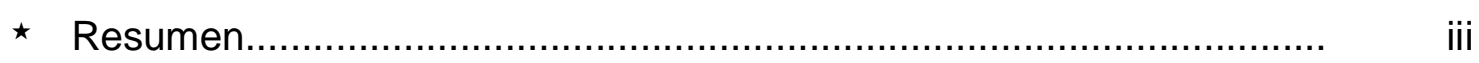

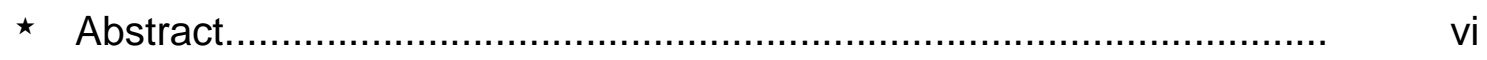

^ 1. Introducción...................................................................................

^ 1. 1. El proceso inflamatorio.......................................................... 1

* 1.2. Vía de activación de NF-kB durante el proceso inflamatorio 2

* 1.2.1. Activación de NF-kB dependiente del receptor TNF- $\alpha$

* 1.2.2. Familia del factor de transcripción NF-kB...................... 5

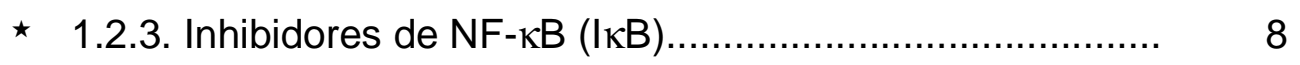

^ 1.2.4. Las IKKs (IKB cinasas).................................................. 12

* 1.3. La obesidad como un proceso inflamatorio............................ 14

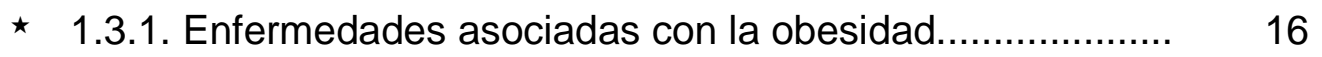

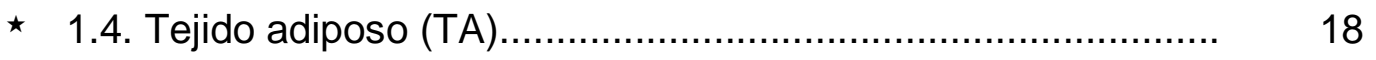

^ 1.4.1. Clasificación.................................................................. 19

^ 1.4.2. Función.................................................................... 19

^ 1.4.3. Moléculas secretadas por el TA...................................... 21

* 1.5. Acción de la glicina como antiinflamatorio y antioxidante........ 26

$\star \quad$ 2. Antecedentes............................................................................ 28

^ 3. Justificación.......................................................................................... 30

^ 4. Hipótesis................................................................................... 31 
^ 5. Objetivo general............................................................................ 31

^ 6. Objetivos particulares........................................................................ 31

^ 7. Diseño experimental........................................................................ 32

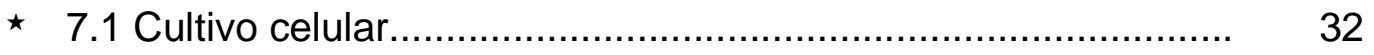

^ 7.2 Cultivos experimentales.......................................................... 32

^ 7.3 Prueba de MTT.......................................................................

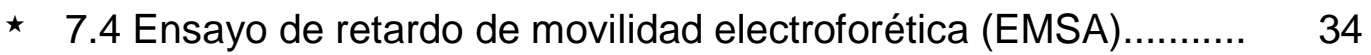

^ 7.5 Western Blot...................................................................

* 7.6 Ensayo por inmunoabsorción ligado a enzimas (ELISA)......... 36

^ 7.7 Análisis estadístico.............................................................. 37

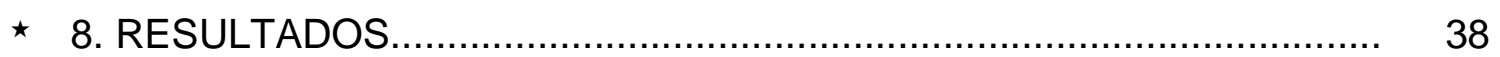

^ 8.1. Diferenciación celular.............................................................. 38

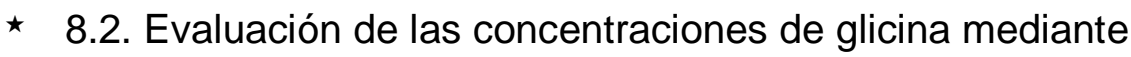
prueba de MTT ................................................................ 39

* 8.3. Efecto de la glicina como regulador de la señalización de IKK- $\alpha \quad 41$

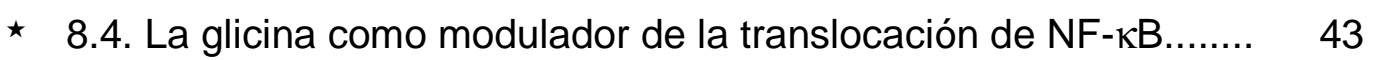

* 8.5. Efecto de la glicina sobre la secreción de Leptina.................... $\quad 45$

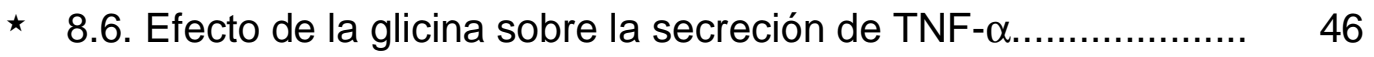

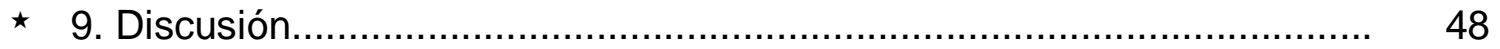

^ 10. Conclusión....................................................................................... 5

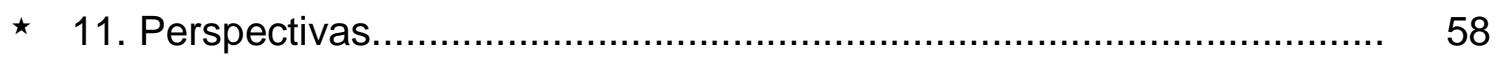

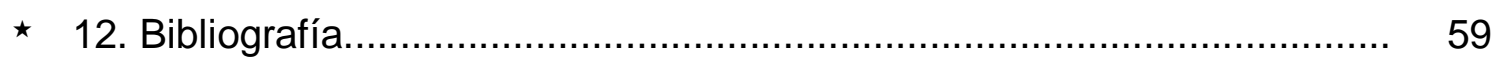




\section{ÍNDICE DE FIGURAS}

Figura 1. Representación esquemática de los miembros de la sub-familia I de $\mathrm{NF}-\mathrm{kB}$

Figura 2. Representación esquemática de los miembros de la sub-familia II de $\mathrm{NF}-\mathrm{kB}$

Figura 3. Representación esquemática de los miembros de la familia $\mid \kappa B$.

Figura 4. Representación esquemática de la activación de la vía NF-kB mediante la liberación del dímero NF-kB del inhibidor IкB

Figura 5. Representación esquemática de los miembros del complejo IKKs.

Figura 6. La Relación entre la expansión del tejido adiposo y el incremento del estado proinflamatorio.

Figura 7. Enfermedades asociadas con la obesidad..................................... 18

Figura 8. Establecimiento de la línea celular 3T3-L1 ................................. 38

Figura 9. Porcentaje de funcionalidad con respecto a la concentración de glicina creciente.

Figura 10. Efecto de la glicina $(10 \mathrm{mM})$ sobre la regulación de IKK- $\alpha$ en adipocitos.

Figura 11. Efecto de la glicina (10 mM) sobre la activación de NF-kB generada por TNF- $\alpha(5 \mathrm{ng} / \mathrm{ml})$ en adipocitos 
Figura 12. Secreción de leptina en los adipocitos pretratados con glicina a $10 \mathrm{mM}$

Figura 13. Secreción de TNF- $\alpha$ en los adipocitos pre-tratados con glicina a $10 \mathrm{mM}$.

Figura 14. Niveles de regulación de la glicina sobre la vía de señalización de TNF- $\alpha$

\section{ÍNDICE DE TABLAS}

Tabla 1. Ejemplo de receptores que se expresan en el TAB

Tabla 2. Ejemplos de proteínas derivadas de adipocitos con funciones endócrinas

Tabla 3. Principales adipocinas y sus acciones. 


\section{RESUMEN}

Introducción: la obesidad ha aumentado de forma significativa en los últimos años y se considera uno de los principales problemas de salud pública a nivel mundial. Durante su desarrollo se presenta una respuesta inflamatoria crónica de bajo grado que genera la activación del factor nuclear kappa B (NF-kB) y la transcripción de genes que codifican para citocinas proinflamatorias, factores de crecimiento y proteínas de fase aguda. Recientemente se ha demostrado que la glicina, un nutriente antioxidante, y protector celular, bloquea el proceso inflamatorio generado por la actividad de macrófagos y adipocitos, los que liberan potentes mediadores proinflamatorios, como factor de necrosis tumoral alfa TNF- $\alpha$, Interleucina 6 (IL-6) y leptina. Además la glicina posee actividad quimioprotectora debido a que reduce eficazmente los niveles séricos de citocinas proinflamatorias y aumenta los niveles de citocinas antiinflamatorias en células 3T3-L1. También se ha demostrado que el tratamiento con glicina disminuye la expresión y secreción de adipocinas proinflamatorias en ratones obesos inducidos con glutamato monosódico (GMS/Ob). Recientemente se ha postulado que estos efectos están relacionados con la reducción en la activación del NF-kB, este factor de transcripción es esencial para la respuesta inflamatoria. Blancas y col. (2012) reportaron que la glicina inhibe la activación de NF-kB, inducida por el TNF- $\alpha$, mediante un mecanismo que implica un aumento parcial de IkB- $\alpha$. En estas condiciones, la glicina suprimió también la expresión de TNF- $\alpha$ e IL-6. En este sentido, la presente investigación se enfoca en estudiar cuál es el nivel de regulación de la glicina sobre la vía de señalización 
canoníca de TNF- $\alpha$ que activa NF- $\mathrm{KB}$ y su asociación con la modulación en la secreción de citocinas.

Objetivo general: determinar si el punto de acción de la glicina en la vía de activación de NF-KB por TNF- $\alpha$ es a nivel de la IKK- $\alpha$, inhibiendo su actividad y regulando la liberación de citocinas proinflamatorias en adipocitos.

Material y métodos: para evaluar el efecto de la glicina en adipocitos se utilizó la línea celular 3T3-L1 (fibroblastos de ratón diferenciados a adipocitos); las células fueron incubadas con TNF- $\alpha(5 \mathrm{ng} / \mathrm{mL})$ durante 30 min (control positivo), BAY (3-[(4metilfenil)sulfonil]-(2E)-propenonitrilo) $(10 \mu \mathrm{M}$, un inhibidor de NF- $\mathrm{KB})$ durante $30 \mathrm{~min}$ (control negativo) y pretratamientos con glicina $(10 \mathrm{mM})$ a los $15,30,45 \mathrm{~min}, 1,2$ y 4 h, seguidos de un estímulo de TNF- $\alpha$ (5 ng/mL durante $30 \mathrm{~min})$. Se realizó la extracción de proteína nuclear y citoplasmática para su cuantificación y análisis. Se aplicó la técnica del Western Blot para la detección de la proteína IKK- $\alpha$. Por el método de ELISA se midió la secreción de TNF- $\alpha$ y leptina. Se realizó EMSA para medir la activación de NF-kB. Los datos se analizaron mediante un análisis de varianza seguido de la prueba de Tukey-Kramer, con un nivel de significancia del $95 \%$.

Resultados: la proteína IKK- $\alpha$ está regulada por la acción de glicina, generando un

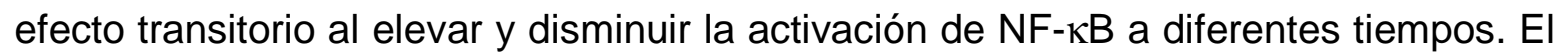
pretratamiento con glicina (de 15 min hasta la 2 h) redujo la secreción de TNF- $\alpha$. Sin embargo, a las $4 \mathrm{~h}$ aumenta la secreción de TNF- $\alpha$ como un efecto secundario, pero que no genera mayor actividad de NF-kB. De igual manera, se observó que el 
pretratamiento con glicina (a 15, 30, 45 min y 2 h) redujo la secreción de leptina y a 1 y 4 h se elevó significativamente hasta llegar a un estado basal parecido al control.

Conclusión: la glicina inhibe la activación de NF-kB inducida por TNF- $\alpha$, por una cascada de fosforilaciones que implican la activación de IKK- $\alpha$ e IKB- $\alpha$, regulando la expresión y secreción de moléculas con carácter proinflamatorio, como TNF- $\alpha$ y leptina. Estos resultados apoyan la idea de que la glicina podría estar regulando el proceso inflamatorio crónico característico de la obesidad a través de un mecanismo que involucra la participación de estos mediadores. 


\section{ABSTRACT}

Introduction: Obesity has been increasing significantly in recent years and is considered one of the major public health problems worldwide. During its development provides an inflammatory response and chronic low-grade activation generates NF- $\mathrm{kB}$ and the transcription of genes encoding pro-inflammatory cytokines, growth factors and acute phase proteins. Has recently been demonstrated that glycine a nutrient antioxidant and cell protective blocks the inflammatory process activity generated by macrophages and adipocytes, which release the potent proinflammatory mediators such as TNF- $\alpha$, IL-6 and leptin. Furthermore the glycine has chemo protective activity because it effectively reduces the serum levels of proinflammatory cytokines and increased inflammatory cytokine levels in 3T3-L1 cells. It has also been demonstrated that treatment with glycine reduces the expression and secretion of pro-inflammatory adipokines in monosodium glutamate (GMS/Ob)induced obese mice. Recently it has been suggested that these effects are related to the reduction in the activation of nuclear factor kappa $B(N F-\kappa B)$, the transcription factor is essential for inflammatory response. Blancas et al. (2012) reported that glycine inhibits TNF- $\alpha$-induced NF- $\mathrm{kB}$ activation by a mechanism involving a partial increase of $I \kappa B-\alpha$. Under these conditions, glycine also suppressed the expression of TNF- $\alpha$ and IL-6. In this sense, this research focused on studying what is the level of regulation of glycine on the canonical signaling pathway of TNF- $\alpha$ that activates NF$\kappa \mathrm{B}$ and its association with modulation of cytokine secretion. 
Objective: Determine if the site of action of glycine in the activation pathway of NF$\kappa B$ by TNF- $\alpha$ is at the level of IKK- $\alpha$, inhibiting its activity and regulating the release of pro-inflammatory cytokines in adipocytes.

Material and methods: To evaluate the effect of glycine was used an adipocyte cell line 3T3-L1 (differentiated mouse fibroblast to adipocytes), cells were incubated with TNF- $\alpha(5 \mathrm{ng} / \mathrm{mL})$ for $30 \mathrm{~min}$ (positive control), BAY (3-[(4-methylphenyl)sulfonyl]-(2E)propenenitrile) $(10 \mu \mathrm{M}$, an inhibitor of $\mathrm{NF}-\mathrm{kB})$ for 30 min (negative control) and pretreatments with glycine $(10 \mathrm{mM})$ at $15,30,45 \mathrm{~min}, 1,2$ and $4 \mathrm{~h}$, followed by stimulation with TNF- $\alpha$ ( $5 \mathrm{ng} / \mathrm{mL}$ for $30 \mathrm{~min}$ ). The extraction of nuclear and cytoplasmic fractions was performed to quantify and to analyze the proteins. IKK- $\alpha$ protein was analyzed by Western Blot. The secretion of TNF- $\alpha$ and leptin was measured by ELISA. EMSA was performed to measure the activation of NF- $\mathrm{kB}$. Data were analyzed using analysis of variance followed by the Tukey-Kramer test, with significance level of $95 \%$.

Results: The protein IKK- $\alpha$ is regulated by the action of glycine, generating a transient effect to raise and reduce the activation of NF-KB at different times. Pretreatment with glycine (15 $\min$ to $2 \mathrm{~h}$ ) reduced the secretion of TNF- $\alpha$. However, after $4 \mathrm{~h}$ there was an increase in the secretion of TNF- $\alpha$ as a secondary effect, but which does not generate higher activity of NF-KB. In this way it was observed that pretreatment with glycine $(15,30,45 \mathrm{~min}$ and $2 \mathrm{~h}$ ) reduced leptin secretion and after 1 and $4 \mathrm{~h}$ it was significantly elevated up to a basal state reaching a level similar to the control. 
Conclusion: Glycine inhibits TNF- $\alpha$-induced NF-KB activation by a cascade of phosphorylations involving the activation of IKK- $\alpha$ and IKB- $\alpha$ regulating the expression and secretion of proinflammatory molecules with character as TNF- $\alpha$ and Leptin. These results support the idea that glycine may be regulating the inflammatory process characteristic of obesity through a mechanism involving the participation of these mediators. 


\section{INTRODUCCIÓN}

\section{1 El proceso inflamatorio.}

La inflamación es la respuesta, del sistema inmunológico de un organismo, al daño causado a sus células y tejidos vascularizados por patógenos bacterianos y por cualquier otro agresor de naturaleza biológica, química, física o mecánica (Weiss., 2002; García-Barreno., 2008). La respuesta inflamatoria comienza con el reconocimiento de las señales intra o extracelulares, que pueden ser de origen infeccioso o inflamatorio, lo que ocasiona la activación celular y la síntesis de proteínas de fase aguda, modificando la respuesta efectora de las células inmunitarias. En la respuesta inmune debida a infecciones, estos mediadores provocan el reclutamiento de células adyacentes a través de un proceso parácrino (Medzhitov., 2008). Cuando la liberación de mediadores excede las fronteras locales, se diseminan y distribuyen a través de la sangre, producen una activación celular generalizada de tipo endócrino que corresponde con el cuadro clínico del síndrome de respuesta inflamatoria sistémica (SIRS). El SIRS es un mecanismo de defensa del huésped que forma parte el proceso de reparación tisular (Brun-Buisson., 2000). Para que esta defensa se inicie de manera eficaz, es necesaria la participación de citocinas con función fundamentalmente proinflamatoria, como TNF- $\alpha$, IL-1 $\beta$ (interleucina 1 beta), interleucina-12 (IL-12), interferón- $\gamma$ (IFN- $\gamma$ ) y, posiblemente, IL-6 (interleucina 6) (Dinarello., 2000). La respuesta inflamatoria inicial está controlada por moléculas inmunorreguladoras, como los inhibidores específicos y los receptores solubles de las citocinas. Las principales citocinas antiinflamatorias son los 
antagonistas del receptor de la IL-1 (IL-1RA), del factor de crecimiento transformante beta (TGF- $\beta$ ) y de las interleucinas 4, 6, 10, 11 y 13 mediando sus efectos por unión al sitio activo o a los sitios alostericos en los receptores para bloquear su efecto proinflamatorio (Opal y DePalo., 2000). Los receptores específicos para IL-1, TNF- $\alpha$ e IL-18 (interleucina-18) se comportan como inhibidores de sus respectivas citocinas proinflamatorias. En condiciones fisiológicas, todas estas moléculas sirven como inmunomoduladoras y, por lo tanto, limitan el efecto potencialmente dañino de la reacción inflamatoria. Así, mientras que en una primera fase predominan los mediadores de efecto proinflamatorio, en fases posteriores predominan mediadores antiinflamatorios. Es decir, la acción de las citocinas depende del momento de su liberación, del lugar en el que actúan, de la presencia de otros elementos competitivos o sinérgicos, de la densidad de sus receptores y de la capacidad de respuesta de ese tejido a cada citocina (Eichacker y col., 2002).

\subsection{Vía de activación de NF-kB durante el proceso inflamatorio.}

La respuesta inmune innata ante las infecciones tiene como principio el reconocimiento de lo ajeno o extraño, pero de forma inespecífica; es decir, actúa igual ante cualquier agente agresor y no varía la intensidad de su respuesta aunque se repita la agresión más de una vez, este tipo de respuesta es fundamental durante la etapa inicial de la defensa del huésped contra la infección por bacterias o virus, antes de que se desarrolle la inmunidad adquirida antígeno específica (Detrick y col., 2008). Cuando entran los agentes patógenos al huésped, las bacterias patógenas 
utilizan un conjunto de proteínas capaces de interferir con las rutas de transducción de señales generando una regulación negativa que evita la eliminación de los microorganismos. Una de las rutas de transducción de señales más importantes en las respuestas inmune, innata y adquirida, es la mediada por la activación del factor nuclear $\kappa B(N F-\kappa B)$. Se ha demostrado que NF-kB no sólo modula la respuesta inmune, también está implicado en la regulación de diversos procesos celulares como inflamación, adhesión, proliferación, diferenciación, apoptosis y oncogénesis (Karin y Lin, 2002).

La activación de NF-kB promueve la transcripción de genes que codifican para citocinas, factores de crecimiento, proteínas de fase aguda, inmunoreceptores, otros factores de transcripción, moléculas de adhesión celular, proteínas virales y reguladores de la apoptosis. Cuando se genera una infección causada por bacterias patógenas o un proceso inflamatorio, la inhibición o activación de NF-кB bloquea 0 induce, respectivamente, la producción de citocinas proinflamatorias y quimiocinas, las cuales tienen como función principal reclutar macrófagos polimorfonucleares al sitio del daño tisular, para eliminar al invasor por fagocitosis o tratar de regular el proceso inflamatorio con la síntesis de citocinas antiinflamatorias.

\subsubsection{Activación de NF-кB dependiente del receptor de TNF- $\alpha$.}

Durante el proceso inflamatorio se activa la vía de señalización del TNF- $\alpha$ y cuando éste se une a su receptor (TNFR1), causa su trimerización y el reclutamiento 
de la proteína asociada a TNFR1 y el dominio de muerte (TRADD), que interactúa con la región citoplásmica de TNFR1 (MacEwan., 2002; Shen y Pervaiz., 2006).

Entonces TRADD interactúa con el factor 2 asociado al receptor de TNF- $\alpha$ (TRAF2). Las otras proteínas importantes en esta ruta, y que probablemente tienen un papel fundamental en la activación de $\mathrm{NF}-\kappa \mathrm{B}$, son la proteína cinasa cinasa cinasa activada por mitógeno 3 (MAPKKK3) y la proteína cinasa de serina/treonina asociada al receptor (RIP). Esto causa la activación de una cinasa específica de IkB (IKK), la cual forma parte de un complejo formado por tres proteínas, IKK $\alpha$, IKK $\beta$ e IKK $\gamma$ [también llamada modulador esencial de NF-KB (NEMO)] con peso molecular de 700 a 900 kDa. IKK $\alpha$ e IKK $\beta$ catalizan la fosforilación de IKB, mientras que NEMO sólo regula esta actividad y no tiene actividad intrínseca de cinasa. Una vez que se activa NF-kB, pasa al núcleo y estimula la transcripción de genes para la síntesis de citocinas, que dan origen a varias reacciones de la respuesta inmune. Normalmente, el NF-kB está unido a una proteína inhibidora denominada $1 \kappa B \alpha$, que impide su translocación al núcleo. La unión de un estimulador inmunitario, como el TNF- $\alpha$, a su receptor de la membrana plasmática conduce a la ubiquitinización de $I \kappa B \alpha$ y a su degradación por el proteosoma 26S, lo cual permite al NF-кB trasladarse al núcleo y activar la síntesis de citocinas.

\subsubsection{Familia del factor de transcripción NF-kB.}


NF-kB es un dímero que se encuentra constituido por proteínas de la familia Rel. Los miembros de esta familia son los encargados de activar la transcripción de los genes diana de la vía. En mamíferos, NF-кB está constituida por 5 miembros

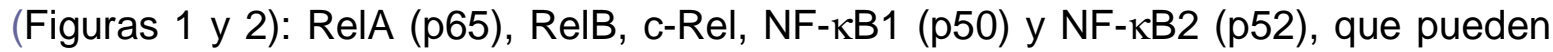
clasificarse en dos subfamilias:

1.- Subfamilia I: incluye los miembros con dominio TAD (del ingés transcription activation domain): RelA, c-Rel y RelB, que son sintetizados en su forma madura (Figura 1).

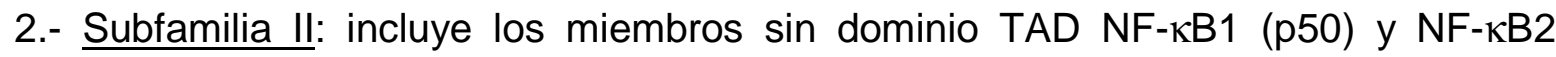
(p52): p50 y p52 son los productos maduros generados a partir de los precursores p105 y p100 (Figura 2).

En cuanto a su estructura, todos los miembros de la familia NF-kB presentan un dominio N-terminal común llamado RHD (del inglés Rel homology domain). Este dominio está formado por 300 aminoácidos y es responsable de la dimerización entre

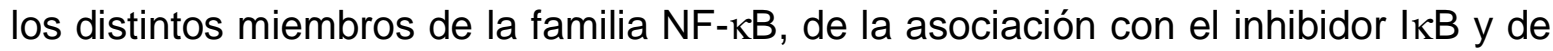
la unión con los motivos $\kappa B$ del DNA; también en este dominio se encuentran las secuencias de localización nuclear llamada NLS (del inglés nuclear localization sequence). Los miembros de la subfamilia I: RelA (p65), c-Rel, y RelB presentan un domino de activación transcripcional llamado TAD, en la región C-terminal. El dominio TAD es necesario para la regulación positiva de la expresión génica (Hayden 
y Ghosh, 2008). Las funciones de los dominios RHD y TAD son muy distintas, ya que en ambos dominios pueden "sufrir" modificaciones postraduccionales que pueden afectar la activación transcripcional de NF-kB, así como su unión con el DNA (Hayden y Ghosh, 2008).

En la mayoría de las células, las proteínas de la familia NF-кB se encuentran en el citosol en forma inactiva, formando homo y/o heterodímeros. El heterodímero RelA/p50 es una de las forma más abundante en las células de los mamíferos (Ghosh y Karin, 2002).

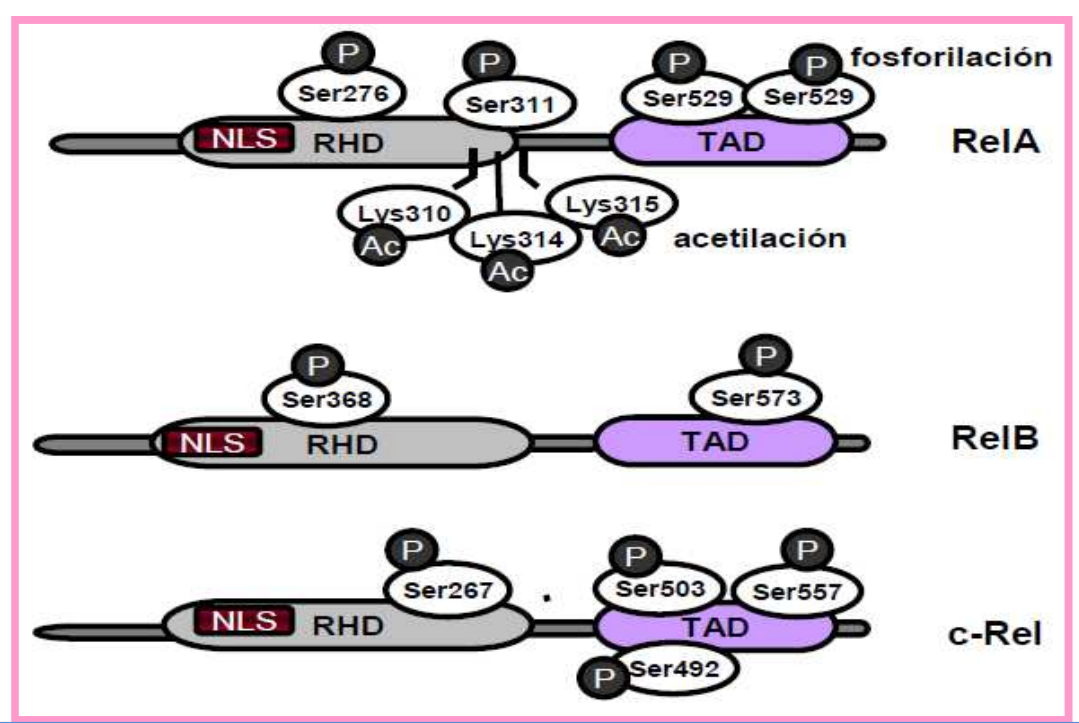

Figura 1. Representación esquemática de los miembros de la sub-familia I de NF-кB. Modificado de Hayden y Ghosh, 2004 y 2008. 


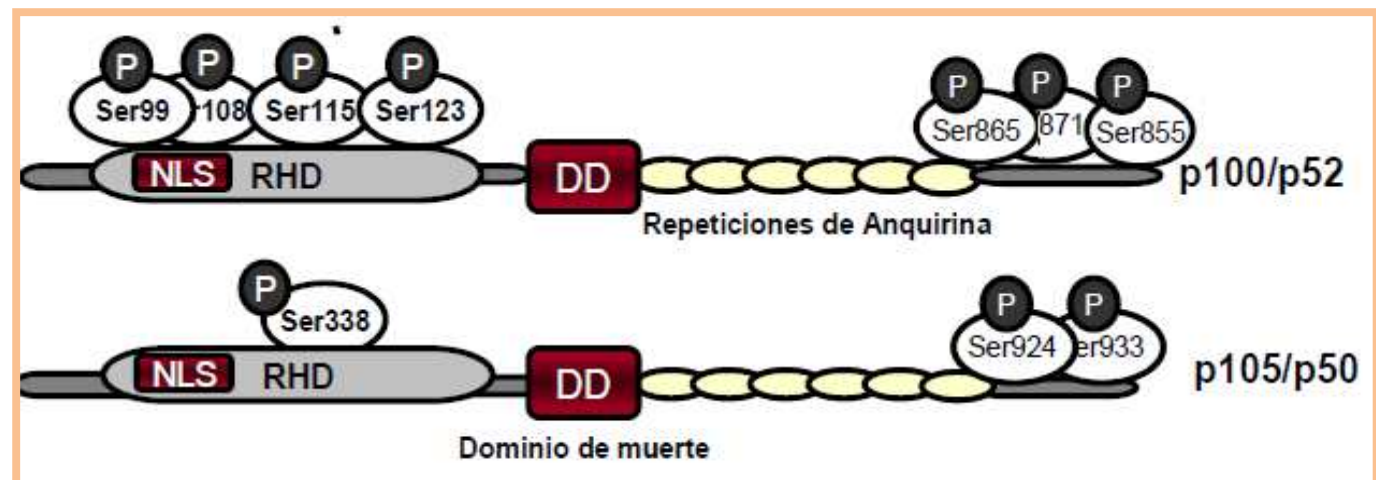

Figura 2. Representación esquemática de los miembros de la sub-familia II de NF-кB. Modificado de Hayden y Ghosh, 2004 y 2008.

En respuesta a varios estímulos en el Sistema Nervioso, entre los cuales podemos destacar los factores neurotróficos, el estrés oxidativo y la inflamación, se puede inducir la translocación nuclear de NF-кB. Una vez en el núcleo, los dímeros NF- $\kappa B$ se unen a los motivos I $\mathrm{kB}$ (GGGRNNYYCC, donde $\mathbf{R}$ representa bases purínicas, $\mathbf{Y}$ representa bases pirimidínicas y $\mathbf{N}$ representa cualquier base) dentro de los promotores de los genes diana, regulando su transcripción mediante la unión de coactivadores o corepresores (Mémet, 2006; Hayden y Ghosh, 2008).

En ausencia de los estímulos activadores de la vía NF-kB, los homodímeros de p50 y/o p52 están unidos a los motivos IKB en los promotores de genes diana, bloqueando su activación. La activación de la vía promueve el desplazamiento de los p50/p50 y p52/p52, dando lugar a la unión de los dímeros NF-kB con dominio TAD (RelA, RelB o c-Rel), activando o reprimiendo la expresión de genes diana. 


\subsubsection{Inhibidores de NF-kB (IKB).}

En la mayoría de los tipos celulares los dímeros de NF-kB se encuentran predominantemente retenidos en el citosol, formando un complejo con proteínas inhibidoras de la familia IкB. Por lo tanto, estas proteínas mantienen la vía NF-кB inactiva. No obstante, en respuesta a diferentes estímulos los dímeros NF-kB del citosol son liberados de su inhibidor y se translocan al núcleo, donde regulan la transcripción de genes específicos (Perkins, 2006).

Los IKBs fueron identificados originalmente como factores que inhiben la actividad

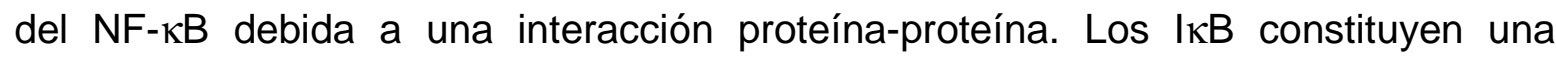
familia de al menos seis isoformas de la proteína inhibidora $1 \kappa B$ : $1 \kappa B \alpha, \quad 1 \kappa B \beta$, I $\mid \kappa \beta \gamma$, $\mid \kappa B \varepsilon, 1 \kappa B \delta$ y $B c \mid 3$ (Figura 3). Todas ellas tienen en común su estructura tridimensional y se distinguen por el número de los dominios de ankirina (Bours y col., 2000). Los

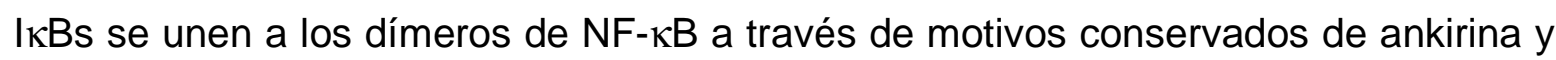
bloquean estéricamente la función de sus secuencias de localización nuclear, lo que permite su retención en el citoplasma. 


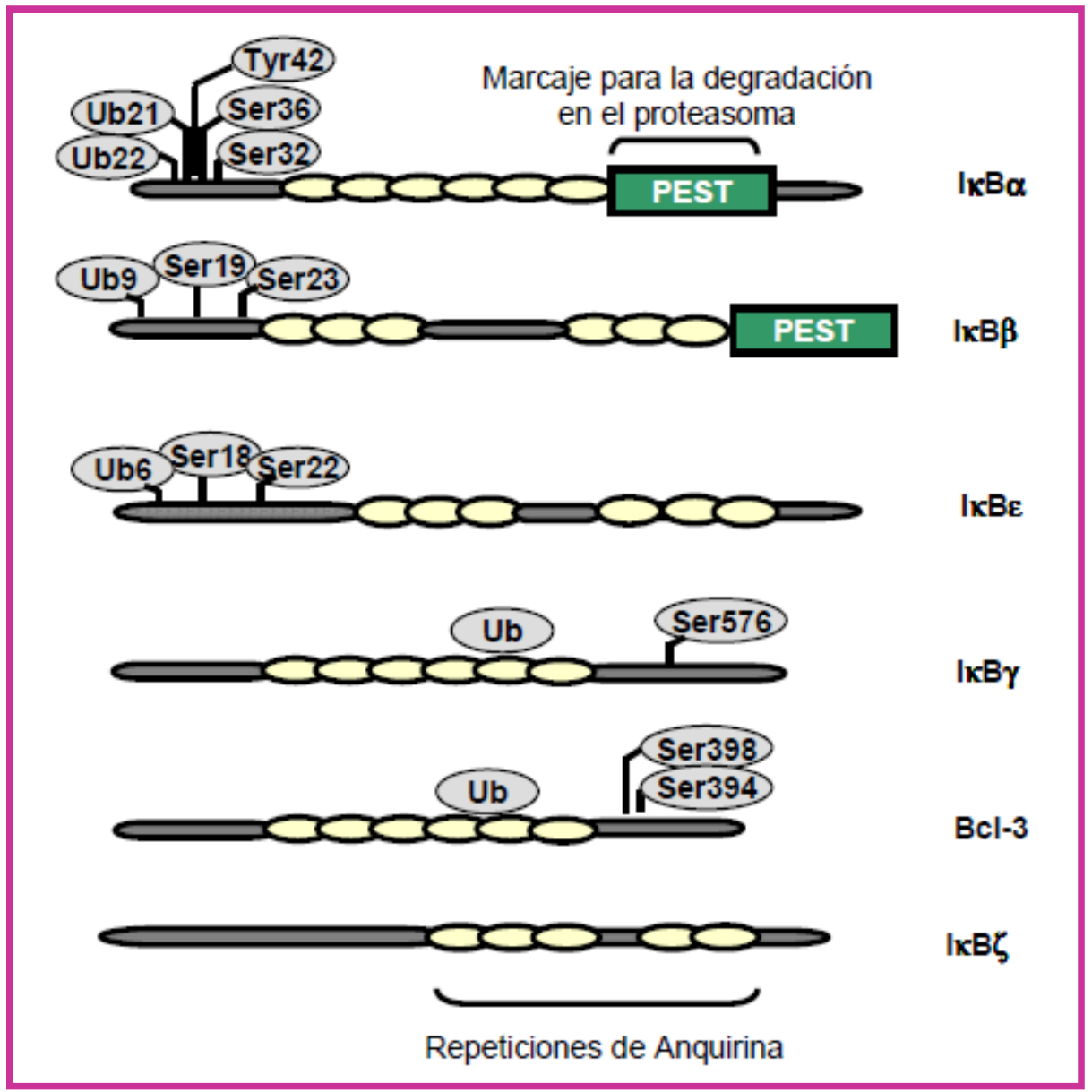

Figura 3. Representación esquemática de los miembros de la familia IKB. Modificado de Hayden y Ghosh, 2004 y 2008.

Para que el NF-kB tenga acceso a su sitio de acción, en el núcleo, el complejo $\mathrm{NF} \kappa \mathrm{B} / \mathrm{l} \kappa \mathrm{B}$ debe ser disociado a través de la fosforilación de su inhibidor. Este proceso que en primera instancia parece tan sencillo, requiere de la participación interactiva también guiada por procesos de fosforilación de proteínas citoplásmicas que se encuentran por arriba en la vía de activación del NF-kB, llamadas cinasas de los inhibidores de IкB (IKK). Los IкBs $\alpha$ y $\beta$ son los mejor estudiados; ambos se fosforilan en respuesta a diferentes estímulos en los residuos de serina: S32 y S36. 
Una vez que los IkBs se han fosforilado, se inicia un proceso de ubiquitinación y degradación en el proteosoma. Este mecanismo libera al NF-kB, ya que al desaparecer el inhibidor se descubre la secuencia de localización nuclear y permite al dímero ser translocado al núcleo, quedando de forma libre para unirse a promotores de genes con sitios de unión a $\mathrm{kB}$ e iniciar la transcripción de los mismos (Bours y col., 2000).

La isoforma IkB $\alpha$ es la que presenta la cinética de degradación más rápida de las proteínas IкB. En su extremo N-terminal se encuentran los residuos susceptibles de fosforilación y también se sitúan los dominios de la proteína que enmascaran las señales de localización nuclear de NF-kB. Tras el estímulo activador de la vía NF-kB, $I_{\kappa} \mathrm{B} \alpha$ es fosforilada en los residuos Ser32 y Ser36 por un complejo de serina-treonina quinasas llamado IKKs (IKB cinasas), que conlleva la liberación del dímero NF-KB. Una vez fosforilado, I $\mathrm{kB} \alpha$ se poliubiquitiniza en los residuos de lisina 21 y 22 , y se degrada en el proteosoma 26S (Hayden y Ghosh, 2004) (Figura 4). Sin embargo, la ausencia de IkB $\alpha$ después de su degradación en el proteosoma es transitoria ya que la activación de NF-kB induce de forma rápida la transcripción de novo del inhibidor al unirse al motivo $\kappa B$ presente en su promotor. Dentro del núcleo, I $\mathrm{kB} \alpha$ pude unir los dímeros NF-kB, disociando el factor del DNA y, gracias a la presencia de la secuencias de exportación nuclear (NES), puede remover las formas activas de NFкB del núcleo y translocarlas hacia el citosol, convirtiéndolas en formas inactivas. 


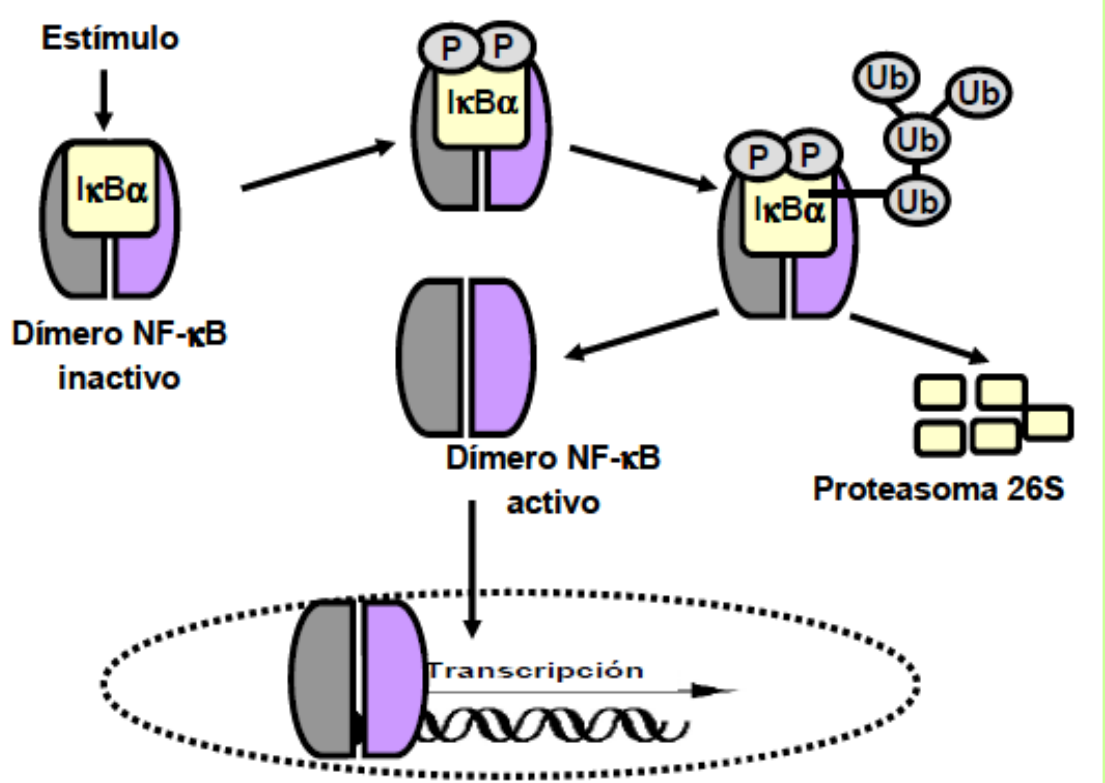

Figura 4. Representación esquemática de la activación de la vía NF-

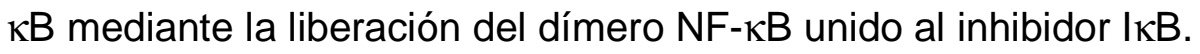

Esto sugiere que $\mathrm{I} \mathrm{KB} \alpha$ impide una activación desmesurada de la vía NF-KB, puesto que es uno de los primeros genes que se transcriben tras la entrada de NF-

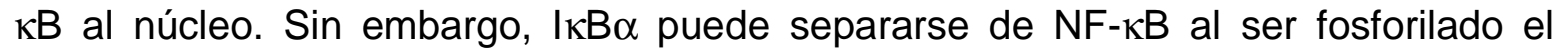
residuo Tyr42 (Bui y Livolsi, 2001; Gallagher y col., 2007; Takada y col., 2003). Esta fosforilación induce la separación del inhibidor $\mid \kappa B \alpha$ de NF-kB pero no su degradación en el proteosoma, como ocurre en respuesta a la fosforilación de los residuos de serina. La activación de la vía NF-kB de esta segunda forma no implica la disminución de los niveles del inhibidor y su síntesis subsecuente en las primeras dos horas tras la activación de la vía. Las subunidades p105 y p100 presentan también repeticiones de dominios ankirina en su extremo C-terminal, por lo que 
pueden considerarse tanto como proteínas inhibitorias como factores de transcripción.

\subsubsection{Las IKKs (IKB cinasas).}

La fosforilación del inhibidor $I_{\kappa} B$ en respuesta a distintos estímulos requiere la activación catalítica de unas serina-treonina cinasas llamadas I $\mathrm{KB}$ cinasas (IKKs). El complejo IKK está constituido por 3 subunidades: dos con dominio cinasa, IKK $\alpha$ e IKK $\beta$, y una subunidad reguladora, NEMO (IKK $\gamma$ ) (Figura 5). Las cinasas IKK $\alpha$ e IKK $\beta$ contienen tres dominios: un dominio cinasa, un dominio helix-loop-helix y un dominio de leucine zipper (Häcker y Karin, 2006). Su dominio catalítico muestra un 65\% de homología: a pesar de ello, las dos cinasas difieren significativamente en sus funciones. El dominio helix-loop-helix es responsable de la unión de IKK $\alpha$ e IKK $\beta$ con NEMO y está implicado en la modulación de su actividad cinasa (May y col., 2000). A través del dominio leucine zipper las IKK $\alpha$ e IKK $\beta$ interactúan formando homo o heterodímeros, siendo la catálisis inducida por los heterodímeros más eficientes que los homodímeros (Huynh y Boddupalli., 2000).

Los mecanismos exactos por los cuales se activan las IKKs son todavía desconocidos. Sin embargo, se conoce que para su activación éstas necesitan estar fosforiladas en dos residuos de serina que se encuentran en el loop de activación (las Ser 177 y 181 para IKK $\beta$, y las Ser 176 y 180 para IKK $\alpha$ ) (Schomer-Miller y col., 2006). Las IKKs tienen diferente distribución celular, mientras IKK $\beta$ e IKK $\alpha$ están 
localizadas en el citosol; solamente IKK $\alpha$, gracias a su secuencia nuclear de localización (NLS) en el dominio cinasa, está localizada en el núcleo (Scotto y col., 2010). Esto sugiere que IKK $\alpha$ podría tener una función nuclear adicional en la activación de NF-kB.

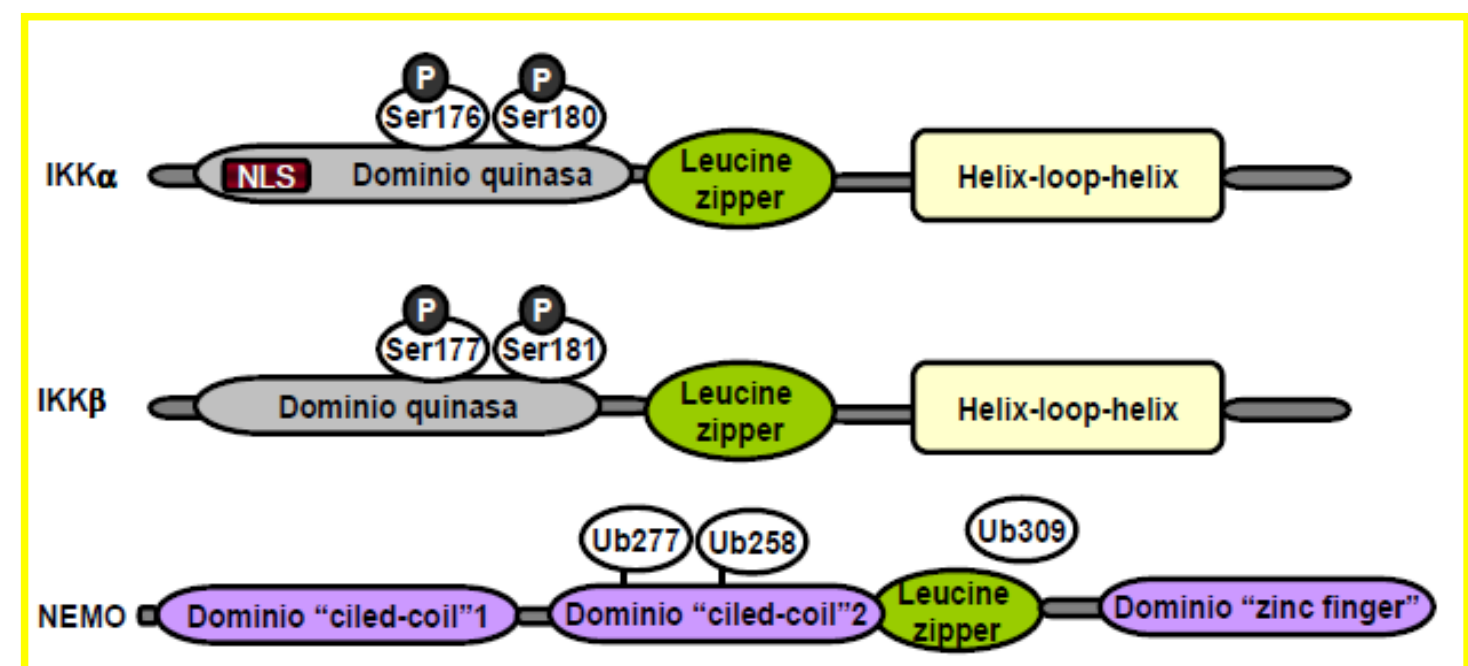

Figura 5. Representación esquemática de los miembros del complejo IKKs. Modificado de Hayden y Ghosh, 2004 y 2008.

Definitivamente el NF-kB es fundamental en la regulación de la respuesta celular ya que pertenece a la categoría de los factores de transcripción primarios de "acción rápida", como son los factores de transcripción que están presentes en las células en un estado de inactivación y que no requieren una nueva síntesis de proteínas para ser activado, esto permite al NF-kB ser la primera respuesta a estímulos celulares nocivos, sin embargo este factor de transcripción controla varios genes involucrados en la inflamación, permaneciendo activado crónicamente en enfermedades inflamatorias, tales como la enfermedad inflamatoria intestinal, la artritis, sepsis, 
gastritis, asma, arterosclerosis y obesidad entre otros, asociados con una elevada mortalidad, especialmente en enfermedades cardiovasculares y esquizofrénicas.

\subsection{La obesidad como un proceso inflamatorio.}

Existen evidencias epidemiológicas de una relación entre obesidad y el estado proinflamatorio. Sin embargo, hasta hace pocos años se ha establecido una vinculación fisiopatológica que demuestra que el exceso de tejido adiposo desencadena una situación de inflamación crónica (Wellen y Hotamisligil, 2003; Hotamisligil, 2006). Esta inflamación difiere de la inflamación clásica, pero posee similitudes en cuanto a las alteraciones en los mediadores de inflamación típicos (pequeñas moléculas asociadas a receptores específicos, como lípidos, aminoácidos modificados, citocinas y factores de crecimiento) y las rutas de señalización (Hotamisligil, 2006). Con el desarrollo de la obesidad se presentan alteraciones en la respuesta inmunitaria ya que se genera un proceso inflamatorio, como ya se había mencionado, el cual es crónico y de bajo grado de intensidad, generado por el tejido adiposo ya "agrandado e inflamado" (Recasens y col., 2004; Sbarbati y col., 2006).

Uno de los procesos que tienen lugar en la inflamación es la infiltración en los tejidos inflamados de células del sistema inmune, tales como neutrófilos, eosinófilos y macrófagos. La hipertrofia de los adipocitos que tiene lugar en la obesidad lleva a un aumento en la producción por parte de los mismos, así como de otras células presentes en el tejido adiposo (fracción estroma-vascular), de una serie de adipocinas/quimiocinas/citocinas proinflamatorias, como TNF- $\alpha$, IL-6, péptido 
amiloide sérico A (SAA), resistina, proteína quimioatrayente de monocitos-1 (MCP-1) y el inhibidor del activador del plasminógeno-1 (PAl-1), entre otros. El aumento en la producción de estas moléculas desencadena efectos locales a nivel del endotelio que conducen a un incremento en la producción de moléculas de adhesión VCAM (molécula de adhesión intercelular 1) e ICAM (molécula de adhesión celular vascular 1) y en la permeabilidad vascular que, en última instancia, se traducen en un aumento en la infiltración de monocitos y la acumulación de macrófagos. A su vez, dichos macrófagos producen más factores quimiotácticos atrayentes de otros macrófagos, lo que se convierte en un auténtico círculo vicioso que perpetúa el estado proinflamatorio (Shoelson y col., 2007; Wellen y Hotamisligil, 2003; Weisberg y col., 2003; Surmi y Hasty, 2008; Nishimura y col., 2008) (Figura. 6).

Los adipocitos estimulados por señales de origen infeccioso o inflamatorio secretan reactantes de fase aguda y más mediadores de inflamación. Entre los factores de inflamación expresados en los adipocitos se incluyen TNF- $\alpha$, IL-6, PAI-1, MCP1, IL-1 $\beta$, IL-8, 10, 15, factor inhibidor de leucemia (LIF), factor de crecimiento del hepatocito (HGF), amiloide sérica A3 (SAA3), factor inhibitorio de la migración de macrófagos (MMIF), moduladores inflamatorios potentes como leptina, adiponectina y resistina, así como la proteína C reactiva (CRP) (Lau y col., 2005; Van Leiden y col., 2002; Yamagishi y col., 2005). 


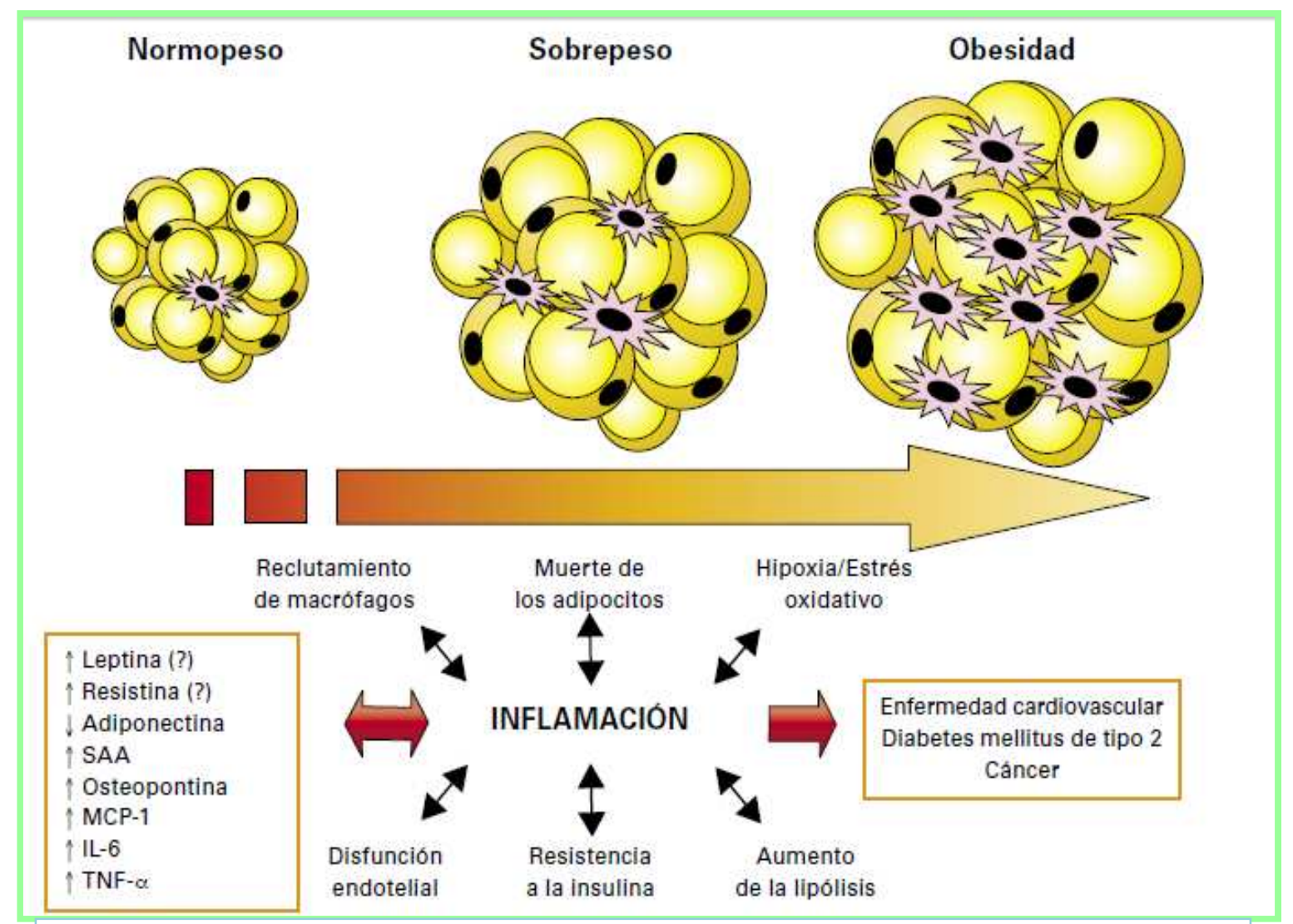

Figura 6. La Relación entre la expansión del tejido adiposo y el incremento del estado proinflamatorio.

La asociación entre obesidad e inflamación se ha confirmado con el hecho de que la pérdida de peso en mujeres obesas tras un año de dieta, ejercicio y cirugía de liposucción, está asociada con una reducción en los niveles circulantes de IL-6 y TNF- $\alpha$ (Nicoletti y col., 2003).

\subsubsection{Enfermedades asociadas con la obesidad.}

La acumulación excesiva o anormal de tejido adiposo provoca profundos cambios en la fisiología del organismo. Estos cambios están asociados a diversas situaciones patológicas o comorbilidades, especialmente a un incremento en la morbilidad y 
mortalidad de los individuos (Figura 7). De manera general, la obesidad se ha asociado con la aparición de enfermedades inflamatorias, cardiovasculares, metabólicas, digestivas, respiratorias, osteoarticulares y neoplásicas.

El incremento de mortalidad está fundamentalmente relacionado con los problemas cardiovasculares, así como con mayor susceptibilidad a padecer otra de las enfermedades crónicas con gran morbimortalidad en el mundo: la diabetes mellitus tipo 2 (DM2), así como algunos tipos de cáncer, entre otras enfermedades (Vainio y col., 2002).

A los pacientes obesos con resistencia a la insulina básicamente se les recomienda un cambio en el régimen alimenticio (mayor consumo de vegetales y menos carbohidratos simples) e incremento en la actividad física. La mayoría de estos pacientes desarrollan complicaciones durante la evolución de la enfermedad, por lo que es importante controlar la presencia de componentes que desencadenan el proceso inflamatorio y la resistencia a la acción de la insulina (Alarcon-Aguilar y col., 2008; Garcia-Macedo y col., 2008). 


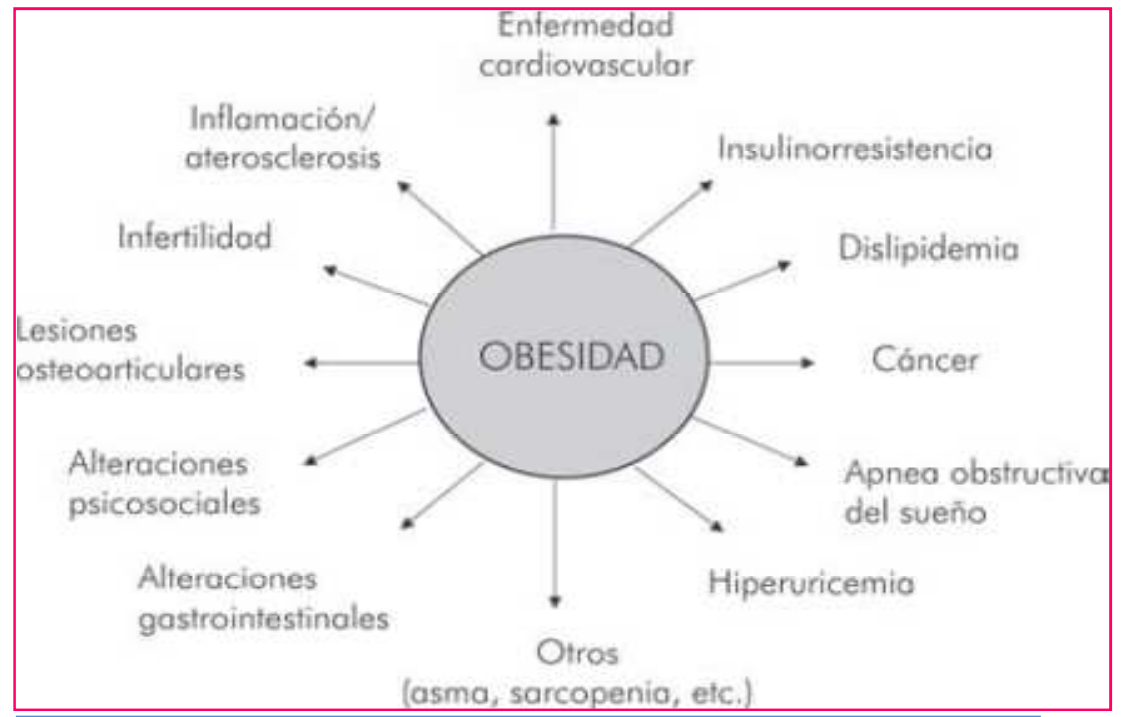

Figura 7. Enfermedades asociadas con la obesidad.

\subsection{Tejido adiposo (TA).}

El acelerado aumento en la incidencia de la obesidad y las complicaciones derivadas de ésta, como la diabetes mellitus y la enfermedad cardiovascular, ha promovido la necesidad de dilucidar los mecanismos involucrados en el desarrollo del tejido adiposo. Tradicionalmente, el tejido adiposo fue visto como el sitio de almacenamiento de energía en forma de triacilglicéridos (TAG) durante la alimentación y liberación de ácidos grasos durante el ayuno para proporcionar combustible a otros tejidos. Sin embargo, hoy es evidente que no sólo es un tejido de almacenamiento de grasa sino que tiene funciones fisiológicas importantes, secretando numerosas proteínas, la cuales participan en la regulación autócrina y parácrina dentro del propio tejido y además tienen efectos en la función de órganos distantes en forma endócrina, tales como el músculo, páncreas, hígado y cerebro, además de participar en la homeostasis de la glucosa y el metabolismo de lípidos, 
también influye en procesos proinflamatorios y antiinflamatorios (Ahima, 2006; Bloomgarden, 2003; Kershaw y Filer, 2004; Lin y col., 2005). Estas proteínas secretadas, las cuales fueron denominadas bajo el término común de adipocinas se hallan implicadas en:

> La regulación del peso corporal (leptina, CRP30/adipoQ).

> La función del sistema inmune (TNF- $\alpha, I L-1, I L-6)$.

> La función vascular (angiotensina e inhibidor del plasminógeno tipo 1).

$>$ La función reproductiva (estrógenos).

> Desarrollo de la resistencia a la insulina (resistina).

\subsubsection{Clasificación.}

Existen dos tipos de tejido adiposo: el tejido adiposo blanco (TAB) y el tejido adiposo marrón (TAM) (Cinti, 2001). Ambos tienen capacidad de metabolizar y almacenar lípidos, pero presentan claras diferencias en cuanto a su morfología, distribución, expresión génica, así como en su función. El tejido adiposo blanco es el órgano específico que almacena la energía sobrante en forma de grasa; mientras que el tejido adiposo marrón, tiene una función fisiológicamente opuesta: permite la disipación de energía en forma de calor (Vega, 2010).

\subsubsection{Función.}

Las funciones básicas del TA son la lipogénesis, lipólisis y secreción de moléculas que participan en múltiples procesos metabólicos. 


\section{Lipogénesis}

La lipogénesis se define como la síntesis de lípidos a partir de hidratos de carbono y otras fuentes de energía consumidas en la dieta. El tejido adiposo blanco es el mayor reservorio energético del organismo. La energía es almacenada en las células grasas en forma de triglicéridos. La principal fuente de triglicéridos para los adipocitos procede de los quilomicrones y las lipoproteínas de muy baja densidad (VLDL) circulantes. Los triglicéridos producidos en exceso entran a la circulación sanguínea en forma de VLDL, favoreciendo el estado de dislipidemia y el desarrollo de complicaciones cardiovasculares comunes en la obesidad. Además, los triglicéridos en exceso se acumulan en el tejido adiposo, provocando hipertrofia de los adipocitos y potencian la resistencia a la insulina. En el humano el proceso de lipogénesis ocurre en el hígado mayormente y es menor en el tejido adiposo, aún bajo condiciones de elevado consumo de hidratos de carbono.

\section{Lipólisis}

El control de la disponibilidad de los ácidos grasos y triglicéridos en el organismo depende de los cambios en las enzimas lipolíticas involucradas en el metabolismo de los lípidos. Durante la lipólisis, los triglicéridos almacenados en el tejido adiposo son hidrolizados hasta ácidos grasos y glicerol. El paso limitante de la lipólisis está controlado por la lipasa sensible a hormonas (HSL). Esta enzima cataliza la hidrólisis de triglicéridos hasta monoglicéridos. Finalmente, éstos son degradados por la monoacilglicerol lipasa. La acumulación de lípidos en el tejido adiposo depende principalmente de la captación de ácidos grasos provenientes de la circulación 
sanguínea (Zechner y col., 2000). Debido a que los lípidos circulan de forma esterificada dentro de las lipoproteínas, la hidrólisis de los triglicéridos por la lipoproteína lipasa (LPL) y por la lipasa derivada del endotelio (Hirata y col., 2000) es un paso crítico en la captación de ácidos grasos, para su posterior reesterificación y acumulación en forma de triglicéridos en el adipocito.

\section{Secreción}

El TA sintetiza y libera gran variedad de compuestos peptídicos y no peptídicos, estableciendo una red molecular de comunicación entre sus propias células y con las de otros tejidos. En este grupo de sustancias secretadas por el tejido adiposo se encuentran proteínas que participan en el metabolismo de los triglicéridos, proteínas que participan en el metabolismo del retinol y del colesterol, proteínas que participan en la coagulación sanguínea, factores con función endócrina, proteínas con actividad autócrina y parácrina que regulan la celularidad del tejido adiposo (González y col., 2002).

\subsubsection{Moléculas secretadas por el TA}

En los últimos años se ha estudiado y ha puesto de manifiesto la gran importancia que tiene el tejido adiposo blanco como productor de ciertas sustancias con acción endócrina, parácrina y autócrina (Fruhbeck y col., 2001); hoy en día se considera que el TAB es un órgano muy dinámico con funciones pleiotrópicas y que es capaz de expresar numerosos receptores (Tabla 1). También expresa y secreta una gran variedad de péptidos bioactivos, conocidos como adipocinas: adipsina, TNF- $\alpha$, 
leptina (Friedman, 2000), inhibidor del activador del plasminógeno-1, resistina (Steppan col., 2001) y adiponectina.

Tabla 1. Ejemplo de receptores que se expresan en el TAB.

\begin{tabular}{|c|c|}
\hline Receptores de membrana para hormonas & $\begin{array}{l}\text { *Insulina } \\
\text { *Glucagón } \\
\text { *GH } \\
\text { *TSH } \\
\text { *Gastrina/CCK-B } \\
\text { * Péptido } 1 \text { similar al glucagón } \\
\text { *Tipo I y II para angiotensina II }\end{array}$ \\
\hline Receptores hormonales nucleares & $\begin{array}{l}\text { *Glucocorticoides } \\
{ }^{*} \text { Hormona tiroidea } \\
{ }^{*} \text { Andrógenos } \\
\text { *Estrógenos } \\
\text { *Progesterona }\end{array}$ \\
\hline Receptor de citocinas & $\begin{array}{l}\text { *Leptina } \\
{ }^{*} \text { Tipo I y II para Adiponectina } \\
{ }^{*} \text { IL-6 } \\
\text { "TNF- } \alpha\end{array}$ \\
\hline Receptor de catecolaminas & $\begin{array}{l}{ }^{*} \beta 1, \beta 2, \beta 3 \\
{ }^{*} 1 \alpha, 2 \alpha\end{array}$ \\
\hline
\end{tabular}

Otras proteínas participan en el metabolismo de los triglicéridos (como la LPL), proteína estimuladora de acilación (ASP), proteína que se une a ácidos grasos (FABP) y la apolipoproteína $\mathrm{E}$ (apo E), proteínas que participan en el metabolismo del retinol y del colesterol (proteína que transfiere ésteres de colesterol, CETP) y proteína que se une a retinol (RBP), proteínas que participan en la coagulación sanguínea (inhibidor del activador del plasminógeno tipo 1 [PAl-1]), factores con función endocrina (hormonas esteroides, angiotensinógeno y adiponectina), proteínas con actividad autócrina y parácrina que regulan la celularidad del tejido 
adiposo (receptor activado por proliferadores de peroxisoma tipo gamma, PPAR- $\gamma$ ), factor de crecimiento transformante tipo beta (TGF $\beta$ ), factor de crecimiento similar a insulina-1 (IGF-1) y hormona de crecimiento (GH), citocinas, moléculas de secreción del tejido adiposo (proteína agouti, monobutirina, factor de crecimiento de fibroblasto (FGF-2), prostaglandinas (PGI2, PGF2 $\alpha$, PGE2) (Tabla 2) (González y col., 2002). Estas citocinas poseen un papel muy importante en la regulación del metabolismo, la reproducción, la función cardiovascular y la inmunidad.

Tabla 2. Ejemplos de proteínas derivadas de adipocitos con funciones endócrinas.

\begin{tabular}{|c|c|}
\hline Citocinas y proteínas relacionadas & $\begin{array}{l}\text { *Leptina } \\
{ }^{*} \text { TNF- } \alpha \\
{ }^{*} \text { IL-6 }\end{array}$ \\
\hline $\begin{array}{l}\text { Proteínas implicadas en el sistema } \\
\text { inmunitario }\end{array}$ & ${ }^{*} \mathrm{MCP}-1$ \\
\hline $\begin{array}{l}\text { Proteínas implicadas en el sistema } \\
\text { fibrinolítico }\end{array}$ & $\begin{array}{l}{ }^{*} \mathrm{PAI}-1 \\
{ }^{*} \text { Factor Tisular }\end{array}$ \\
\hline $\begin{array}{l}\text { Proteínas del Complemento y } \\
\text { relacionadas }\end{array}$ & $\begin{array}{l}\text { *Adipsina (Factor D del complemento) } \\
{ }^{*} \text { Factor B del complemento } \\
\text { *ASP } \\
{ }^{*} \text { Adiponectina }\end{array}$ \\
\hline $\begin{array}{l}\text { Lípidos y proteínas del metabolismo y } \\
\text { transporte de lípidos }\end{array}$ & $\begin{array}{l}{ }^{*} \text { CEPT (Cholesterol Ester Transfer } \\
\text { Protein) } \\
\text { *Apolipoproteína E } \\
{ }^{*} \text { FFA } \\
{ }^{*} \text { aP2 }\end{array}$ \\
\hline $\begin{array}{l}\text { Enzimas implicadas en el metabolismo } \\
\text { Esteroideo }\end{array}$ & $\begin{array}{l}{ }^{*} \text { Citocromo p450 dependiente de } \\
\text { aromatasas } \\
{ }^{*} 17 \beta \mathrm{HSD} \\
{ }^{*} 11 \beta \mathrm{HSD} 1\end{array}$ \\
\hline Proteínas de RAS & *AGT \\
\hline
\end{tabular}


La secreción de estas citocinas por el TA está regulada entre otros factores por el ayuno, la ingesta y la obesidad. De esta manera, el adipocito se ha convertido en el integrador central del programa metabólico del organismo y está completamente establecido que la función endocrina del adipocito ejerce una influencia directa sobre otros órganos clave, como el cerebro, el hígado o el músculo esquelético. Las adipocinas son diversas en cuanto a su estructura proteínica y a su función fisiológica, establecen una red de comunicaciones con tejidos y órganos; como ya se ha ido mencionando, esta comunicación se da a diversos niveles como en el músculo esquelético, la corteza adrenal, el cerebro y el sistema nervioso simpático (Ronti y col., 2006). Incluyen citocinas clásicas, factores de crecimiento y quimitotácticos, factores del complemento y proteínas comprometidas en la regulación de la presión arterial, la homeostasis vascular, el metabolismo lipídico, la homeostasis de glucosa, la angiogénesis y la osteogénesis (Tabla 3).

Tabla 3. Principales adipocinas y sus acciones.

\begin{tabular}{|l|l|l|}
\hline \multicolumn{1}{|c|}{ ADIPOCINA } & \multicolumn{1}{|c|}{ ACCIÓN VASCULAR } & \multicolumn{1}{|c|}{ ACCIÓN METABÓLICA } \\
\hline Adiponectina & $\begin{array}{l}\text { - ICAM-1, VCAM-1, NF } \kappa \beta \\
\text { - Transf. macrófagos } \rightarrow \text { CE, } \\
\text { - Proliferación y migración } \\
\text { SMC, } \\
\text { - Adhesión de monocitos a CE }\end{array}$ & $\begin{array}{l}\text { - sensibilidad a la insulina } \\
\text { - Cambios inducidos por } \\
\text { TNF- } \alpha \text { en moléculas de } \\
\text { adhesión }\end{array}$ \\
\hline Angiotensinógeno & $\begin{array}{l}\text { - Biodisponibilidad NO, } \\
\text { angiogénesis. } \\
\text { IL-6 }\end{array}$ & - Hipertensión \\
& $\begin{array}{l}\text { MCP-1, MCSF. ICAM-1, VCAM-1, } \\
\text { - ICAM-1, E-selectina, VCAM- } \\
\text { 1,MCP-1 } \\
\text {-Proliferación y migración SMC }\end{array}$ & $\begin{array}{l}\text { - Diferenciación de } \\
\text { preadipocitos, } \\
\text { PCRhepática. }\end{array}$ \\
\hline & & $\begin{array}{l}\text { - Señales de transducción } \\
\text { de receptor de insulina } \\
\text { - Gluconeogénesis }\end{array}$ \\
\hline
\end{tabular}




\begin{tabular}{|l|l|l|}
\hline Leptina & $\begin{array}{l}\text { - Proliferación y migración de } \\
\text { CE y VSMC, acumulación de } \\
\text { ROS y estrés oxidativo, } \\
\text { apoptosis de VSMC, } \\
\text { angiogénesis, liberación de } \\
\text { MCSF }\end{array}$ & $\begin{array}{l}\text { - Presión sanguínea, tono } \\
\text { simpático. } \\
\text { - Lipogénesis, } \text { 个Lipólisis. } \\
\text { - Insulino resistencia }\end{array}$ \\
\hline PAl-1 & - Formación de trombo & \\
\hline Resistina & $\begin{array}{l}\text { - ET-1, expresión de moléculas } \\
\text { de adhesión. }\end{array}$ & $\begin{array}{l}\text { - Insulino resistencia en } \\
\text { músculo e hígado. } \\
\text { - Captación de glucosa y } \\
\text { acción de insulina. }\end{array}$ \\
\hline TNF- $\alpha$ & $\begin{array}{l}\text { - Biodisponibilidad de NO, } \\
\text { vasodilatación } \\
\text { - NFkB, VCAM-1, ICAM-1, E- } \\
\text { selectina, MCP-1 y VSMC, } \\
\text { Apoptosis CE }\end{array}$ & $\begin{array}{l}\text { - Diferenciación de } \\
\text { adipocitos, señalización de } \\
\text { insulina. } \\
\text { - Insulino resistencia y } \\
\text { lipólisis, AGL } \\
\text { - Síntesis de adiponectina }\end{array}$ \\
\hline
\end{tabular}

La regulación en la síntesis de estas citocinas durante el desarrollo de la inflamación ha permitido el estudio de los agentes capaces de inhibir este fenómeno llevado al desarrollo de fármacos que actúan a diferentes niveles. Una fuente importante de productos con importancia farmacológica la constituyen los productos naturales, minerales $\mathrm{y}$, en tal sentido, la búsqueda de principios activos o compuestos químicos con posible efecto antiinflamatorio (Bremner y Heinrich., 2002).

Una gran variedad de sustancias naturales y sistémicas poseen actividad quimiopreventiva o quimioprotectora. Esta actividad suele atribuirse a sus propiedades antioxidantes o antiinflamatorias, como es el caso de la glicina. 


\subsection{Acción de la glicina como antiinflamatorio y antioxidante.}

La glicina, un aminoácido no esencial y uno de los más simples, cuyo grupo lateral es un hidrógeno; se forma a partir del dióxido de carbono y del amoniaco por la acción de la glicina sintasa, que es una enzima cuyo cofactor es el fosfato de piridoxal. También se puede formar a partir de la L-serina por la acción de la serinahidroximetil-transferasa además ha sido utilizada como producto nutricional que participa en la biosíntesis de ácidos nucleicos, ácidos biliares, porfirinas, creatina fosfato y otros aminoácidos. Este aminoácido ha mostrado ser protector contra la lesión celular atenuando el influjo de calcio libre citosólico y la generación de superóxido por los neutrófilos; también participa en la producción de TNF- $\alpha$ en macrófagos alveolares, actúa contra la hipoxia de los túbulos renales proximales, la isquemia, la falla renal aguda, en el daño por reperfusión en el tejido cardiaco y hepático, proporciona citoprotección contra la lesión hepatocelular por depleción de ATP y minimiza las lesiones hepáticas después de la exposición crónica al alcohol. También mejora la supervivencia en el choque endotóxico, protege de la hepatotoxicidad por D-galactosamina, previene el estado hipermetabólico y la hipoxia hepática (Matilla y col., 2002).

La glicina bloquea el proceso inflamatorio sistémico que se origina en una amplia variedad de estados patológicos tales como trauma, shock hemorrágico, sepsis, quemaduras y procesos de isquemia/reperfusión, debido a la actividad de macrófagos que liberan potentes mediadores inflamatorios tales como citocinas 
tóxicas y eicosanoides, los cuales desempeñan un importante papel en la respuesta inflamatoria progresiva.

Se ha reportado que la glicina reprime la expresión de citocinas proinflamatorias, como el TNF- $\alpha$ e IL-6 en células de Kupffer (Spittler y col., 1999), estimulando la respuesta antiinflamatoria por el aumento de la interleucina 10 (Spittle y col., 1999). Por lo tanto, la glicina podría ser útil en diversos trastornos inflamatorios, como la reducción de resistencia a la insulina en obesidad, que se caracterizan por un estado inflamatorio crónico. Se considera que la glicina es un aminoácido que funciona como un nutriente antioxidante y protector celular y que su uso representa una de las alternativas que busca aminorar las complicaciones macro y microvasculares características de los pacientes obesos (Matilla y col., 2002), ya que ha demostrado tener propiedades antiinflamatorias tanto in vivo como in vitro (Alarcon-Aguilar y col., 2008; Garcia-Macedo y col., 2008). 


\section{ANTECEDENTES}

El uso de la glicina representa una de las alternativas que busca mejorar la calidad de vida de las personas predispuestas a la obesidad, por lo que es importante conocer cuáles son los mecanismo de acción de la glicina por los cuales disminuye el proceso inflamatorio y previene el daño celular (Matilla y col., 2002).

En las investigaciones realizadas por nuestro grupo se ha encontrado que el tratamiento con glicina en los adipocitos de ratón de la línea celular 3T3-L1 provoca disminución en los niveles de expresión del RNAm de IL-6, TNF- $\alpha$ y resistina, así como aumento de adiponectina, citocia que es considerada como antiinflamatoria y que es secretada exclusivamente por el adipocito; también se incrementó la expresión de PPAR- $\gamma$, uno de los reguladores principales de adiponectina (Garcia-Macedo y col., 2008). En otros estudios se demostró que, en ratones obesos inducidos con glutamato monosódico (Ob/GMS), la administración de glicina disminuye la expresión y secreción de adipocinas proinflamatorias, observándose tendencia a incrementar adiponectina (Alarcon-Aguilar y col., 2008).

También se demostró que existe un efecto benéfico de la glicina al disminuir el estrés oxidativo medido por la peroxidación de lípidos en pacientes diagnosticados con síndrome metabólico (SM) y una aparente reducción en la expresión del gen SOD2, estudio realizado en la Unidad de Investigación Médica en Bioquímica del Hospital de Especialidades en el Centro Médico Nacional Siglo XXI (Loza et al., 2007). En esta 
misma Unidad de Investigación se realizó un estudio con pacientes diagnosticados con DT2 a los cuales se les dio una dosis de $5 \mathrm{~g} /$ día de este aminoácido durante tres meses. Se encontró que existe una disminución significativa en los niveles de TNF- $\alpha$ e incremento en un $43 \%$ de los niveles de IFN- $\gamma$ en relación con el grupo que recibió placebo. Además, los pacientes tratados con glicina mostraron una disminución significativa en hemoglobina glicada y citocinas proinflamatorias (Cruz y col., 2008)

En trabajos recientes realizados por nuestro laboratorio se observó que el pretratamiento con glicina regula la actividad del NF-kB. La medición del inhibidor del NF-kB (IкB- $\alpha)$ nos permitió demostrar que la inhibición de este factor de transcripción por el uso de glicina al parecer es por la vía canónica del NF-kB (Blancas-Flores y col., 2012). También se ha observado que el factor de transcripción NF-kB regula la expresión de genes asociados con la respuesta inmune, la inflamación y la defensa celular. Entre ellos, cabe destacar los genes para: citocinas (por ejemplo, TNF- $\alpha$ ), receptores de citocinas, moléculas de adhesión, factores de crecimiento hematopoyéticos y una gran cantidad de genes que codifican para proteínas antiapoptótica (Blancas-Flores y col., 2012).

Por lo que se propone el estudio de la vía de señalización de TNF- $\alpha$ y las proteínas que participan en ella principalmente la cinasa IKK- $\alpha$ ya que forma parte del complejo IKK un sitio de regulación que permite la activación de NF-kB el cual es considerado como un blanco terapéutico para el bloqueo de la inflamación. 


\section{JUSTIFICACIÓN}

La obesidad constituye un problema de salud pública, por lo que se considera como uno de los problemas importantes a estudiar (Kopelman, 2000). Se ha demostrado que la obesidad es uno de los principales factores de riesgo para desarrollar resistencia a la insulina y DT2; estas enfermedades están acompañadas de un proceso inflamatorio que genera una desregulación en los adipocitos, produciendo altos niveles de citocinas proinflamatorias y bajos de antiinflamatorias. Se han estudiado diferentes fármacos para disminuir la obesidad a nivel mundial pero el frecuente fracaso de estas medidas ha propiciado la búsqueda de recursos terapéuticos adicionales. Uno de estos recursos es el empleo de la glicina en el tratamiento de los pacientes obesos y diabéticos que presentan complicaciones micro y macrovasculares.

A partir de los conocimientos que se tienen hasta ahora sobre glicina en relación con su efecto antiinflamatorio, como regulador de la expresión de citocinas proinflamatorias (TNF- $\alpha$ e IL-6) (Spittler y col., 1999; Alarcon-Aguilar y col., 2008) y como inhibidor de la activación de NF-kB estimulada por TNF- $\alpha$, se consideró interesante profundizar en el estudio de su mecanismo de acción a diferentes tiempos de incubación, buscando explicar a nivel molecular la acción benéfica de la glicina en los procesos inflamatorios citados. 


\section{HIPÓTESIS}

Si el pretratamiento con glicina regula la actividad del inhibidor IאB, disminuyendo la activación de NF-KB estimulada por TNF- $\alpha$ y consecuentemente la expresión de citocinas proinflamatorias, entonces la glicina debe estar regulando la actividad de IKK- $\alpha$ y la síntesis de las citocinas en adipocitos.

\section{OBJETIVO GENERAL}

Determinar si el punto de acción de la glicina en la vía de activación de NF-kB por TNF- $\alpha$ es a nivel de la IKK- $\alpha$, inhibiendo su activación y regulando la liberación de citocinas proinflamatorias en adipocitos.

\section{OBJETIVOS PARTICULARES:}

c Elucidar si el pretratamiento de glicina regula la actividad de IKK- $\alpha$ evitando la activación de NF-kB por estimulo de TNF- $\alpha$ en los adipocitos.

e Estudiar el curso temporal de la inhibición en la activación de NF-kB por glicina.

@ Determinar si la secreción de citocinas inflamatorias (TNF- $\alpha$ y leptina) está asociada con la inactivación de NF-kB por acción de la glicina. 


\section{DISEÑO EXPERIMENTAL}

En este proyecto se utilizó como modelo el cultivo celular de fibroblastos de ratón diferenciados a adipocitos de la línea celular 3T3-L1.

\subsection{Cultivo celular.}

Los adipocitos se diferenciaron a partir de fibroblastos precursores denominados preadipocitos. Los fibroblastos de la línea 3T3-L1 de ratón se cultivaron a confluencia a $37^{\circ} \mathrm{C}$ con atmósfera de $5 \%$ de $\mathrm{CO}_{2}$ en placas de seis pozos con medio DMEM ("Dulbecco's modified Eagle's medium") ( $9 \times 10^{4}$ células por placa), piruvato de sodio $1 \mathrm{mM}$, glutamina $2 \mathrm{mM}$, aminoácidos no esenciales $(0.1 \mathrm{mM})$, gentamicina $10 \mu \mathrm{g} / \mathrm{ml}$, complementado con $10 \%$ de suero fetal bovino. Después de dos días a confluencia (día 0), la diferenciación de fibroblastos a adipocitos se indujo con metilhidroxibutilxantina (MIX, $0.5 \mathrm{mM})$, dexametasona (DX, $0.25 \mu \mathrm{M})$ e insulina (5 $\mu \mathrm{g} / \mathrm{ml}$ ) en DMEM con $10 \%$ de suero fetal bovino. Al segundo día se cambio el medio adicionado con insulina ( $5 \mu \mathrm{g} / \mathrm{ml})$, sin MIX, sin DX y se mantuvo por dos días más. A partir del cuarto día, el medio sin suplementó de insulina se remplazó cada dos días.

\subsection{Cultivos experimentales.}

Se utilizaron cultivos sin ninguna condición y otros con tratamiento.

a) Cultivos testigo. La línea celular de fibroblastos de ratón 3T3-L1 se cultivó en medio DMEM con $10 \%$ de suero fetal bovino, bajo las mismas condiciones ya 
mencionadas, para posteriormente realizar la diferenciación. El cultivo fue utilizado como testigo.

b) Cultivos con tratamiento. Se utilizaron cultivos de fibroblastos diferenciados a adipocitos bajo las mismas condiciones indicadas anteriormente. Una vez en estado de adipocitos se les aplicaron los siguientes tratamientos: se utilizó un control en el cual las células solamente se diferenciaron y fueron mantenidas sólo con cambios de medio; un tratamiento con TNF- $\alpha(5 \mathrm{ng} / \mathrm{ml})$ durante $30 \mathrm{~min}$ el cual se utilizó como control positivo; un tratamiento con BAY $10 \mu \mathrm{M}$ (inhibidor de NF- $\mathrm{kB}$ ) durante $30 \mathrm{~min}$ antes de adicionar TNF- $\alpha$, como control negativo. $Y$ por último, los grupos que recibieron glicina $10 \mathrm{mM}$ a diferentes tiempos de incubación (15, 30, 45 min,1, 2 y $4 \mathrm{~h}$ de pretratamiento) posteriormente se adicionó TNF- $\alpha$ (30 min) a cada uno.

Los experimentos se realizaron por triplicado para cada uno de los tratamientos. Después de cada uno de los tratamientos, el medio de incubación se recuperó, centrifugó y se almacenó a $-70^{\circ} \mathrm{C}$ hasta su uso. Las células se desprendieron y se procedió a la extracción de proteína citoplasmática y nuclear para su análisis por Western Blot y EMSA.

\subsection{Prueba de MTT.}

Esta prueba se basa en la reducción metabólica del bromuro de 3-(4,5dimetiltiazol-2-ilo)-2,5-difeniltetrazol (MTT) a formazán, está reacción es realizada por 
la enzima mitocondrial succinato deshidrogenasa, que indica que la cantidad de células vivas es proporcional a la cantidad de formazán producido. Dicha prueba permite determinar la funcionabilidad mitocondrial de las células tratadas. Este método fue desarrollado por Mosmann en 1983, siendo modificado en 1986 por Francois Denizot y Rita Lang. Hasta la fecha es muy utilizada para medir supervivencia y proliferación celular.

Se utilizaron placas de 96 pozos para realizar una siembra celular bajo las mismas condiciones (diferenciación de fibroblastos a adipocitos). Posterior a la diferenciación se aplicaron diferentes concentraciones de glicina (5, 10, 15, $20 \mathrm{mM})$, se incubaron las células a $37^{\circ} \mathrm{C}$ y $5 \%$ de $\mathrm{CO}_{2}$ durante 24 horas. Transcurrido el tiempo se retiró el medio y se colocaron $100 \mu \mathrm{L}$ de medio fresco para realizar la prueba de MTT utilizando el kit CellTiter $96^{\circledR} A Q_{\text {ueous }}$ One Solution Cell Proliferation Assay, siguiendo las instrucciones recomendadas por el kit.

\subsection{Ensayo de retardo de movilidad electroforética (EMSA).}

Se utilizó está técnica para valorar la actividad del factor de transcripción NF-kB mediante la unión especifica al DNA. Para ello fue necesario la obtención de extractos nucleares de las células y la incubación de las proteínas nucleares a una sonda de oligonucleótido específico (región consenso 5'-AGT-TGA-GGG-GAC-TTTCCC-AGG-3', Santa Cruz) marcado radiactivamente $\left({ }^{32} \mathrm{P}\right)$. 
Para los ensayos se utilizó un gel no desnaturalizante de acrilamida al $7.5 \%$ y se realizó una pre-recorrida0. a 80 volts durante 1 h. La unión de la sonda premarcada al factor NF-kB presente en cada uno de los extractos nucleares se llevó a cabo en un volumen final de $20 \mu \mathrm{l}$, se mezclaron $10 \mu \mathrm{g}$ de proteína de extracto nuclear, $1 \mu \mathrm{g}$ de poli dl/dC, $1 \mu \mathrm{g}$ de pd (N)6 y $10 \mu \mathrm{g}$ de albumina sérica bovina. Se incubaron en solución amortiguadora HDKE (Hepes $20 \mathrm{mM} \mathrm{pH} \mathrm{7.9,} \mathrm{KCl} 50$ mM, EDTA 1 mM y ditiotreitol $5 \mathrm{mM})$. La sonda marcada $(10-50,000 \mathrm{cpm})$ se adicionó al final para iniciar la reacción de unión. Después de incubar durante 10 min a temperatura ambiente, se adicionó una solución de ficol al 15\% complementada con colorantes para electroforesis para detener la reacción. La muestra se corrió en un gel con TBE 1X a $200 \mathrm{~V}$, por $2 \mathrm{~h}$. Una vez terminada la corrida, el gel fue secado en un equipo Gel Dryer Model 583, BIO-RAD, a $90^{\circ} \mathrm{C}$ con vacio (HydroTe ch $^{\mathrm{TM}}$ Vacuum Pump) durante $1.5 \mathrm{~h}$. Una vez desecado el gel se colocó en un cassette de auto-radiografía Phosphorimager (Molecular Dynamics/GE) durante toda una noche y la imagen se reveló en un equipo Thyphon 9400 (Molecular Dynamics/GE). Posteriormente las imágenes fueron analizadas por densitometría.

\subsection{Western Blot.}

La técnica del Western Blot se realizó para el análisis de proteínas. La especificidad de la unión antígeno - anticuerpo permitió la detección de una única proteína dentro de una mezcla compleja de otras proteínas. En la actualidad se utiliza como criterio de identificación positivo de una proteína especifica en una 
mezcla compleja y para obtener datos cualitativos y semicuantitativos sobre la misma.

Para cada ensayo se utilizaron $30 \mu \mathrm{g}$ de los extractos de proteínas citoplasmáticas en buffer de muestra (Tris-HCl 125 mM pH 6.8, SDS 1\% v/p, glicerol $10 \% \mathrm{v} / \mathrm{v}$, azul de bromofenol $0.1 \%$, 2-mercaptoetanol $2 \% \mathrm{v} / \mathrm{v}$ ) por $5 \mathrm{~min}$. Las muestras fueron separadas en geles de poliacrilamida con SDS al $12 \%$ y posteriormente transferidas a una membrana de Hybond-ECL (Amersham, Buckinghamshire, UK). Las membranas se incubaron con anticuerpo primario de ratón anti-IKK- $\alpha$ Santa Cruz), diluido 1:250 en TBS. Después se lavaron las membranas y posteriormente se incubaron con un anticuerpo secundario acoplado a peroxidasa (Pierce, Rockford). Las señales generadas por quimioluminiscencia fueron detectadas utilizando el sistema de "Super-Signal" (Pierce, Rockford, II)". Las señales de las manchas se cuantificaron por densitometría.

\subsection{Ensayo por inmunoabsorción ligado a enzimas (ELISA).}

Se realizó la prueba de ELISA para la cuantificación de citocinas provenientes del medio de cultivo celular de adipocitos con los diferentes tratamientos ya mencionados.

Para esta prueba se utilizó la metodología descrita por el proveedor (R\&D Systems) para leptina y TNF- $\alpha$. Tanto las muestras a evaluar como la curva estándar fueron 
incubadas en distintos pocillos de la microplaca recubiertos con un anticuerpo dirigido contra la molécula a evaluar. Luego de la incubación y de los lavados correspondientes se incubó con un segundo anticuerpo dirigido contra otro epítope del analito conjugado con peroxidasa. Finalmente se realizaron lavados y posteriormente se incubó la microplaca con un cromógeno y se detuvo la reacción para leer la microplaca a una absorbancia de $450 \mathrm{~nm}$ y $550 \mathrm{~nm}$. Los límites de detección y los valores normales fueron proporcionados por el fabricante.

\subsection{Análisis estadístico.}

Los resultados fueron expresados como media \pm S.E.M. Las diferencias significativas fueron determinadas mediante ANOVA, utilizando una prueba complementaria de Tukey, con una significancia estadística del 95\% $(p \leq 0.05)$, utilizando el software GraphPad Prims 5. 


\section{RESULTADOS}

\subsection{Diferenciación celular.}

En la Figura 8 se muestran dos microfotografías a 40X que muestran la diferenciación de la línea celular 3T3-L1 de fibroblastos a adipocitos.

a)

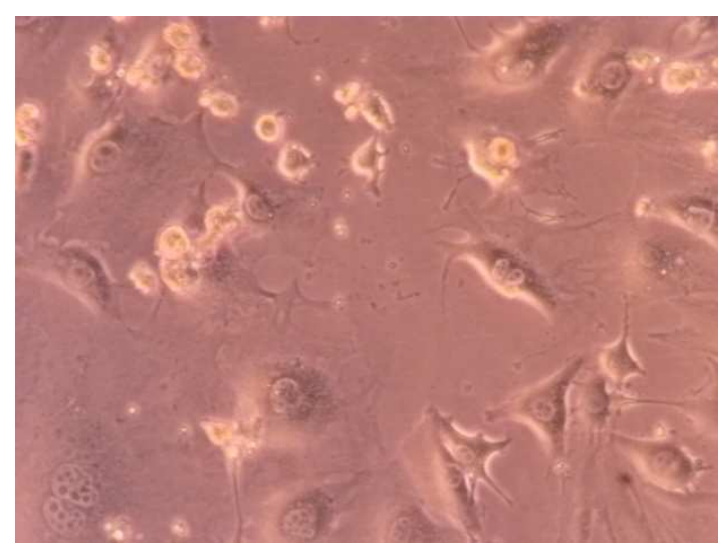

b)

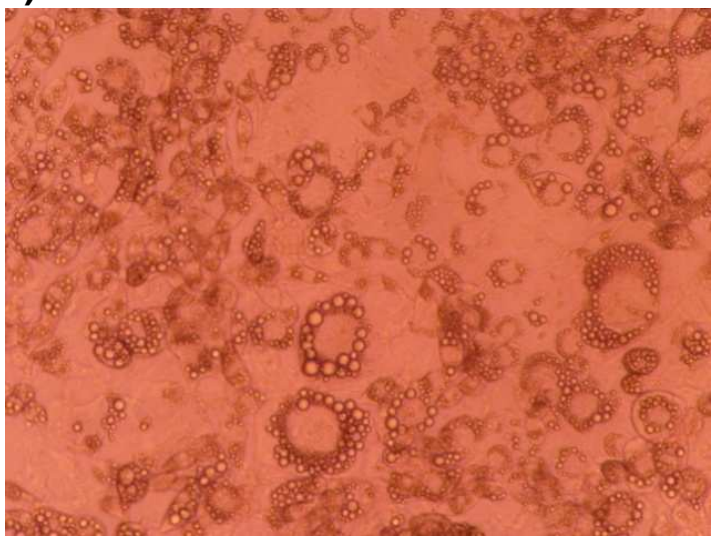

Figura 8. Establecimiento de la línea celular 3T3-L1 día 4. a) Fibroblasto (preadipocito). b) Adipocito día 10.

a) Fibroblastos precursores de adipocitos (preadipocitos) durante los primeros cuatro días, cultivados a confluencia a $37^{\circ} \mathrm{C}$ con atmósfera de $5 \%$ de $\mathrm{CO}_{2}$ en medio DMEM ("Dulbecco's modified Eagle's medium"), piruvato de sodio 1 $\mathrm{mM}$, glutamina $2 \mathrm{mM}$, aminoácidos no esenciales $(0.1 \mathrm{mM})$, gentamicina $(10 \mu \mathrm{g} / \mathrm{ml})$, complementado con $10 \%$ de suero fetal bovino.

b) Adipocitos, obtenidos al décimo día por la inducción con metilhidroxibutilxantina (MIX, $0.5 \mathrm{mM})$, dexametasona (DX, $0.25 \mu \mathrm{M})$ e insulina (5 $\mu \mathrm{g} / \mathrm{ml})$ en D-MEM con $10 \%$ de suero fetal bovino. 


\subsection{Evaluación de las concentraciones de glicina mediante prueba de MTT.}

Se realizó la prueba de MTT (3 - (4,5-dimetiltiazol-2-il) - bromuro de 2,5difeniltetrazolio) a diferentes concentraciones de glicina $(5,10,15,20 \mathrm{mM})$.

En la Figura 9 se observa el porcentaje de funcionalidad celular. Se apreciaron diferencias significativas en las concentraciones de 5, 15, $20 \mathrm{mM}$ con respecto al control, en el caso de las concentraciones de $5 \mathrm{mM}$ y $20 \mathrm{mM}$ se obtuvo un porcentaje de funcionalidad de la célula por debajo del $90 \%$ y en la de $15 \mathrm{mM}$ por arriba del $100 \%$, por lo que no se consideraron como concentraciones óptimas ya que era necesario que presentaran una viavilidad mayor del 95\% y cercana al $100 \%$ semejante al control.

Por otro lado, la concentración de $10 \mathrm{mM}$ tuvo una mayor similitud en el porcentaje de funcionalidad de las células con respecto al control, por lo que se consideró pertinente trabajar con esta concentración. De hecho, esta concentración es la misma que ha sido usada en otras investigaciones (García-Macedo y col., 2008). 


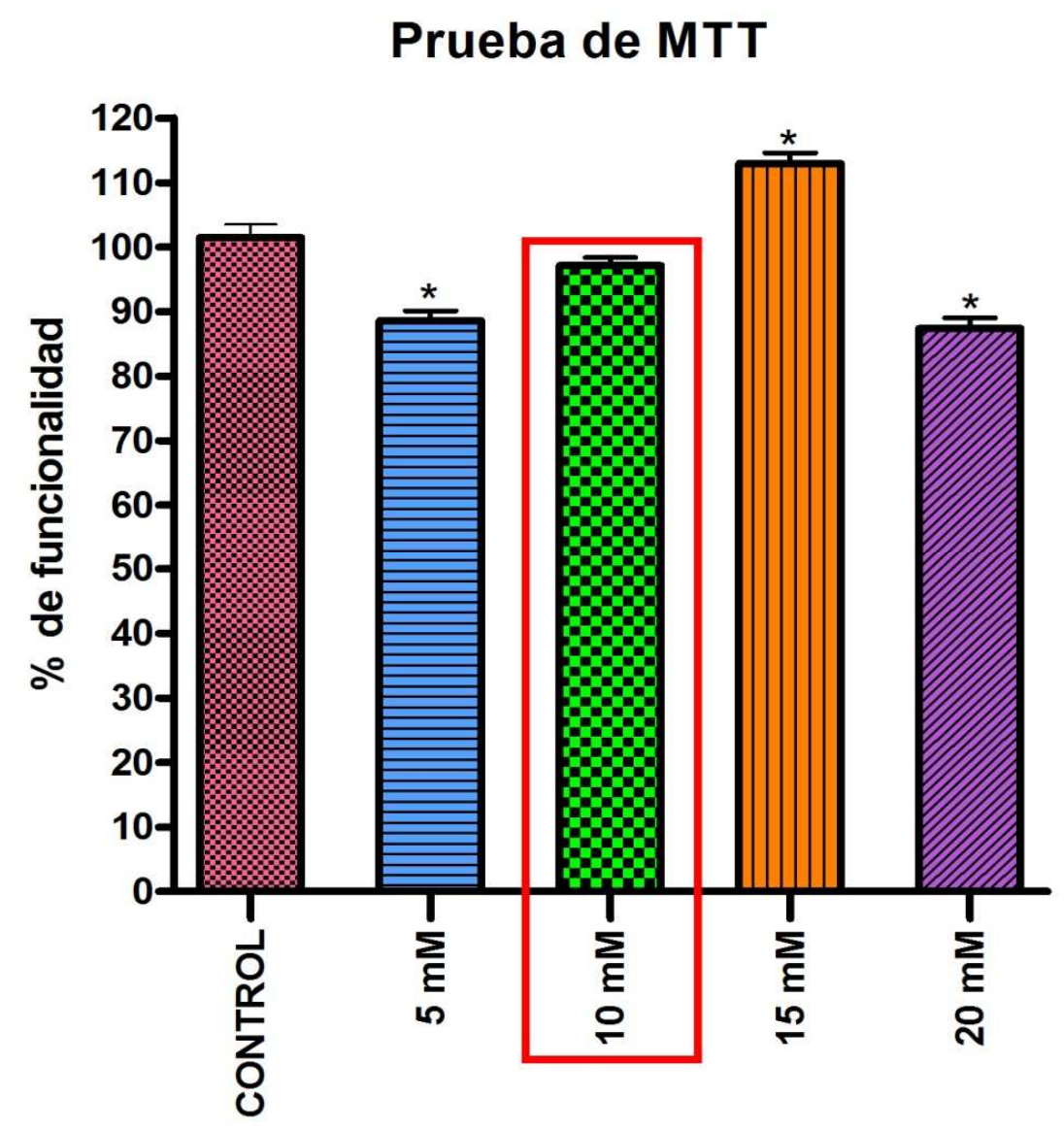

Figura 9. Porcentaje de funcionalidad de los adipocitos con respecto a la concentración de glicina creciente. Las celulas tratadas con glicina 10 mM mostraron una viabilidad de valor exacto \pm por lo que fue elegida para tratar a las celulas diferenciadas a adipocitos. ( $n=6$; * significativamente diferente con respecto al control, $\mathrm{p}<0.05)$. 


\subsection{Efecto de la glicina como regulador de la señalización de IKK- $\alpha$.}

Por medio de la técnica de western blot se detectó la presencia de IKK- $\alpha$ en el contenido citoplasmático de los adipocitos, a los cuales se les aplicó un pretratamiento con $10 \mathrm{mM}$ de glicina a diferentes tiempos (15, 30, $45 \mathrm{~min}, 1,2$ y $4 \mathrm{~h}$ ) seguido de un pulso de TNF- $\alpha$ durante 30 min (Figura 10a).

En la Figura 10b, el histograma muestra que en el control la presencia de IKK- $\alpha$ es baja, el tratamiento con TNF- $\alpha$ estimula la presencia de dicha cinasa; el pretratamiento con glicina a 15 min no modifica el efecto de TNF- $\alpha$; sin embargo sí se observaron diferencias significativas a $30 \mathrm{~min}, 1$ y $2 \mathrm{~h}$ con respecto a TNF- $\alpha$, tiempos en los que se aprecian los niveles más altos de la presencia de IKK- $\alpha$ ya que aumentan $85 \%$ aprox. También se demostró que el pretratamiento con glicina a las 4 h disminuye significativamente el contenido citoplasmático de IKK- $\alpha$ en un $26 \%$ con respecto a TNF- $\alpha$.

Se observó que entre el pretratamiento con glicina a las $4 \mathrm{~h}$ y el control negativo BAY inhiben aprox $40 \%$ IKK- $\alpha$ presente en el citoplasma de los adipocitos con respecto al tratamiento con TNF- $\alpha$. 
a)

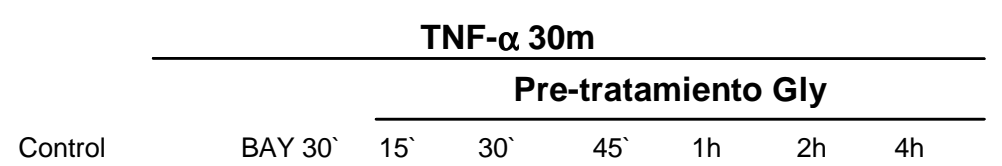

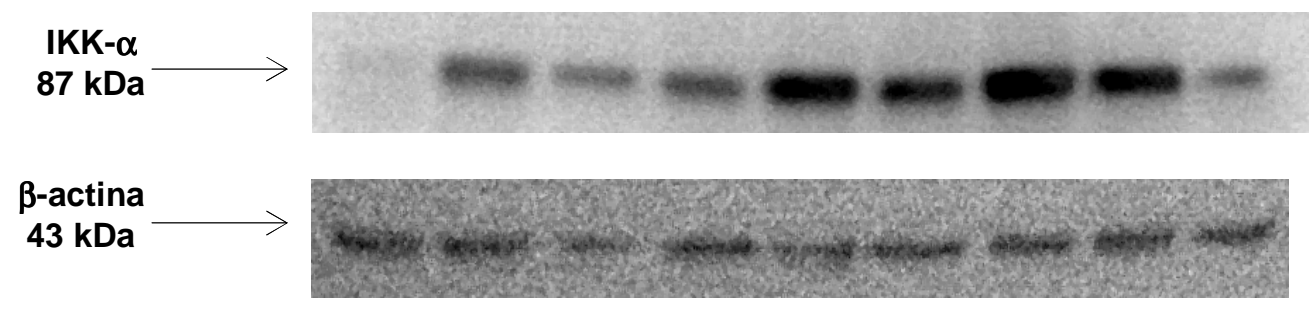

b)

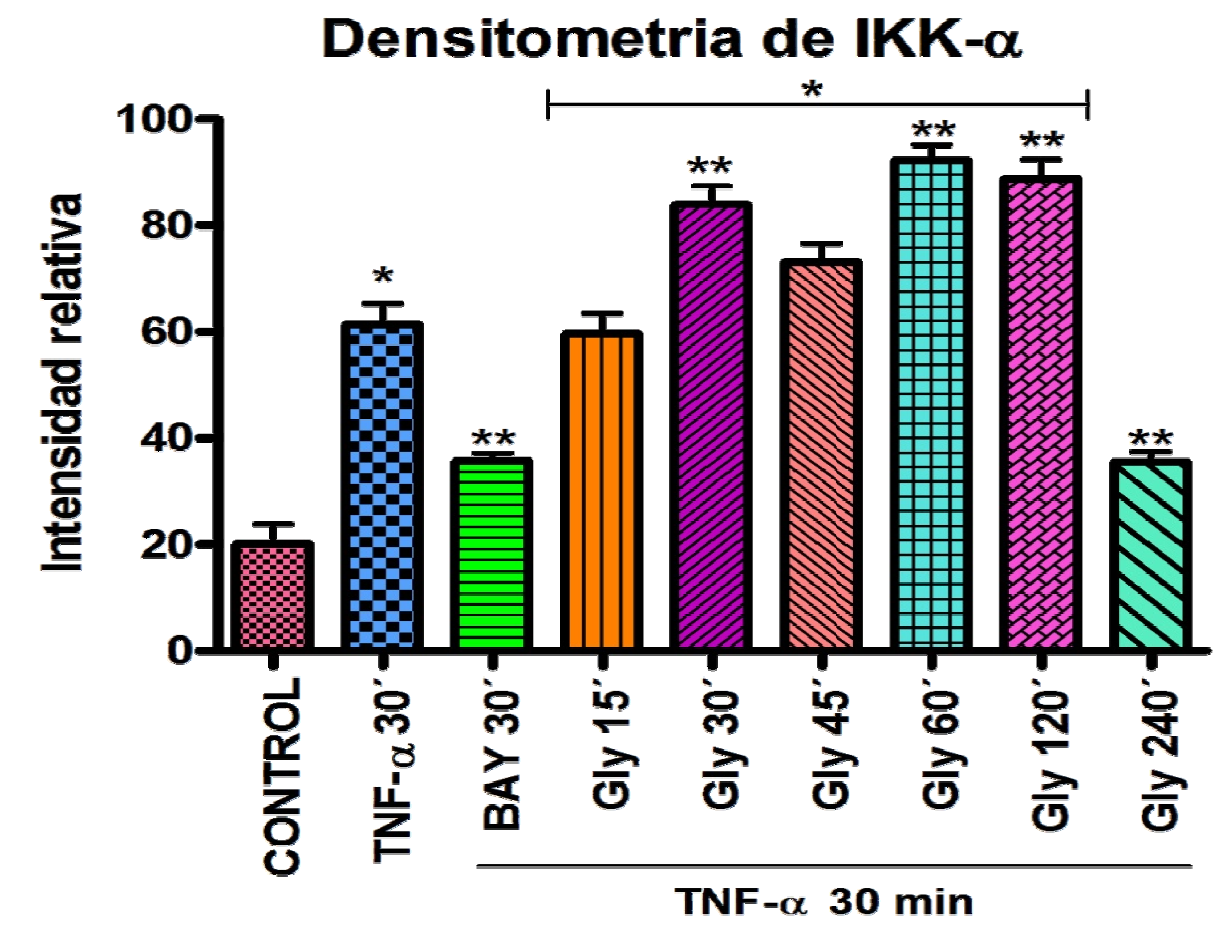

Figura 10. Efecto de la glicina $(10 \mathrm{mM})$ sobre la regulacuón de IKK- $\alpha$ en adipocitos.

a) Localización de IKK- $\alpha$ en extractos citosólicos después del pretratamiento con glicina a diferentes tiempos mediante la tecnica de western blot. b) Densitometria de la localización de IKK- $\alpha$ mediante western blot. El histograma muestra media \pm S.E.M. de tres experimentos independientes. "Significativamente diferente con respecto al control, $\mathrm{p}<0.05,{ }^{* *}$ Significativamente diferente con respecto a TNF- $\alpha, \mathrm{p}<$ 0.05 . 


\subsection{La glicina como modulador de la translocación de NF-kB.}

Los resultados obtenidos mediante el ensayo de retardo de movilidad electroforética nos permitió evaluar la actividad de unión de NF-kB al ADN. A los adipocitos se les aplicó un pretratamiento con $10 \mathrm{mM}$ de glicina a diferentes tiempos $(15,30$ y 45 min, 1,2 y 4 h) seguido de una estimulación de TNF- $\alpha$ durante 30 min (Figura 11a).

El análisis realizado por densitometría demostró que el pretratamiento con glicina a los tiempos ya mencionados tuvieron diferencias significativas con respecto al control (Figura 11b).

En comparación con TNF- $\alpha$, el pretratamiento con glicina por 30 min y $1 \mathrm{~h}$ disminuye significativamente el nivel de activación de NF-kB. Sin embargo, se observó que el pretratamiento con glicina a la hora es el tiempo en el que obtuvo una mayor disminución del la activación de NF-kB hasta un $52 \%$ con respecto a TNF- $\alpha$ (Figura 11b).

De igual manera se observó que el pretratamiento con glicina por $2 \mathrm{~h}$ genera un efecto contrario ya que aumenta significativamente la activación de NF-kB hasta un $65 \%$ con respecto a TNF- $\alpha$, tiempo en el que también se observó que hubo una mayor activación de NF-kB con respecto a los otros tratamientos (Figura 11b). 
a)

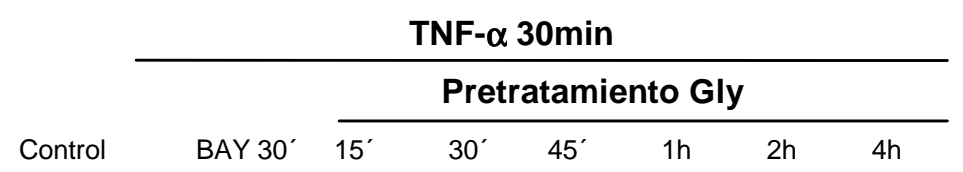

$\mathrm{NF}-\mathrm{kB} \longrightarrow$

n.s

Oligo

libre

b)

Densitometria de NF-кB

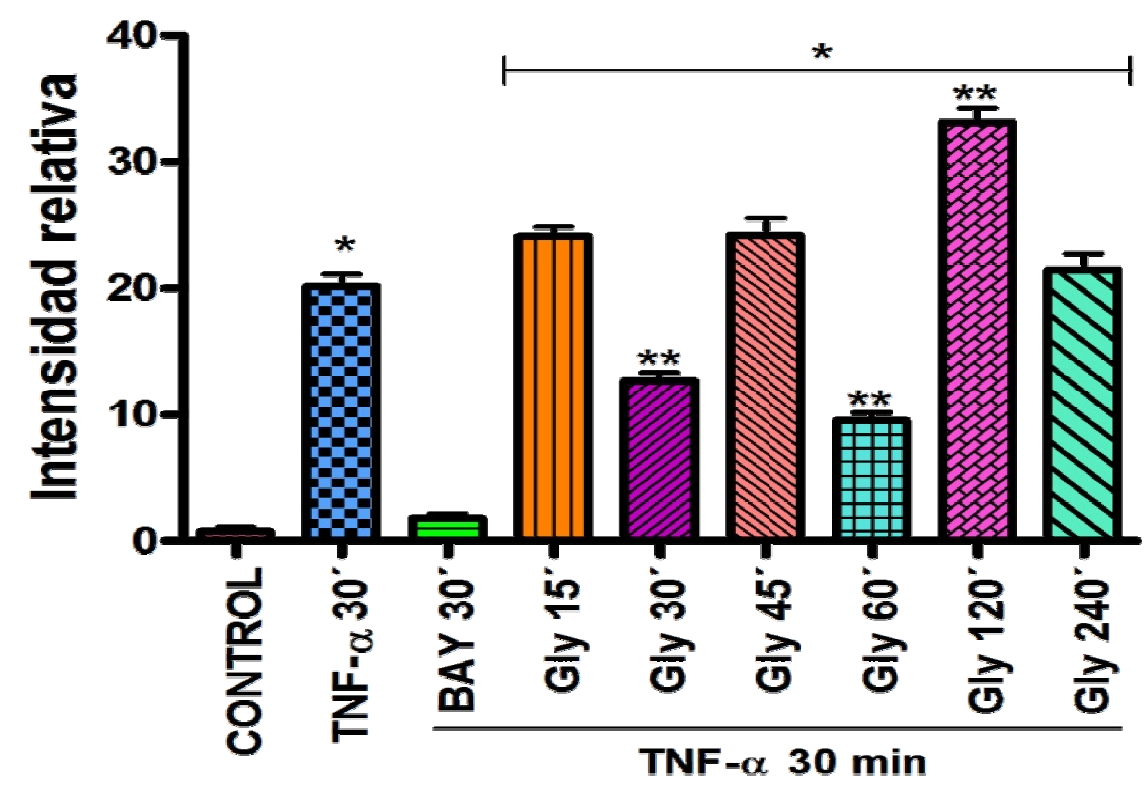

Figura 11. Efecto de la glicina $(10 \mathrm{mM})$ sobre la activación de NF-kB generada por TNF- $\alpha(5 \mathrm{ng} / \mathrm{ml})$ en adipocitos. a) Maracaje de NF- $\mathrm{KB}$ en extractos nucleares de células pretratadas con glicina y estimuladas con TNF- $\alpha$ mediante EMSA. b) Analisis 
del EMSA por densitometria de la union de NF- $\mathrm{kB}$ al ADN. El histograma muestra media \pm S.E.M. de tres experimentos independientes. *Significativamente diferente con respecto al control, $\mathrm{p}<0.05,{ }^{*}$ Significativamente diferente con respecto a TNF- $\alpha$, $p<0.05$.

\subsection{Efecto de la glicina sobre la secreción de Leptina.}

Se midió la secreción de leptina en los adipocitos tratados con glicina a 10 mM a diferentes tiempos (15, 30 y $45 \min , 1,2$ y 4 h), seguido de una estimulación de TNF- $\alpha$ durante 30 min, mediante la prueba de ELISA.

En la Figura 12 se muestra que en el control la secreción de leptina es de 137 $\mathrm{pg} / \mathrm{ml}$, en el caso del tratamiento con TNF- $\alpha$ (control positivo) muestra una disminución en la secreción de leptina con respecto al control por debajo de los 50 pg/ml; el pretratamiento con glicina a los 15, 30 y 45 min, así como a las 2 h no modifica la secreción de leptina con respecto a TNF- $\alpha$.

De igual manera se observó que el pretratamiento con glicina por $1 \mathrm{~h}$ aumentó hasta un $254 \%$ y a las $4 \mathrm{~h}$ hasta un $164 \%$, incrementos estadísticamente significativos con respecto a TNF- $\alpha$. A estos tiempos se aprecian los niveles más altos de la secreción de leptina regresando a concentraciones basales. 


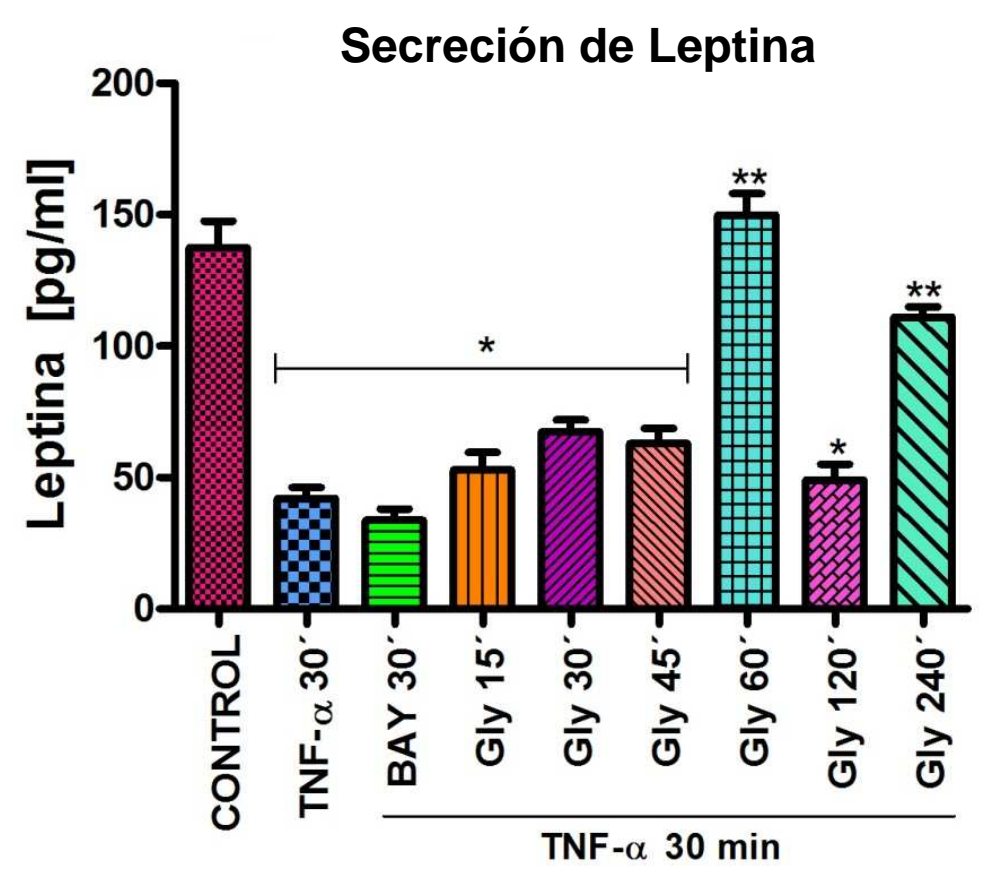

Figura 12. Secreción de leptina en los adipocitos pretratados con glicina a $10 \mathrm{mM}$. Cuantificación de la secreción de leptina en el sobrenadante del medio de cultivo de Ios adipocitos mediante la prueba de ELISA. El histograma muestra media \pm S.E.M. de una $n=6$. *Significativamente diferente con respecto al control, $p<0.05$, ${ }^{* *}$ Significativamente diferente con respecto a TNF- $\alpha, p<0.05$.

\subsection{Efecto de la glicina sobre la secreción de TNF- $\alpha$.}

Se midió la secreción de TNF- $\alpha$ en los adipocitos tratados con glicina a $10 \mathrm{mM}$ a diferentes tiempos (15, 30 y 45 min, 1, 2 y 4 h) mediante la prueba de ELISA.

En la Figura 13 se muestra que la secreción de TNF- $\alpha$ es muy baja sin embargo no es nula, en el tratamiento con TNF- $\alpha$ se observa una mayor secreción de TNF- $\alpha$ por arriba de los $145 \mathrm{pg} / \mathrm{ml}$ ya que la misma molécula promueve su secreción, se 
observa que el pretratamiento con glicina a 15, 30, 45 min, 1 y 2 h disminuye significativamente la secreción de TNF- $\alpha$ con respecto al control positivo TNF- $\alpha$. Sin embargo, se observó que a 15 y 30 min la secreción de TNF- $\alpha$ fue mínima por debajo del $8 \%$ con respecto a TNF- $\alpha$, regresando a concentraciones basales similares al control no tratando.

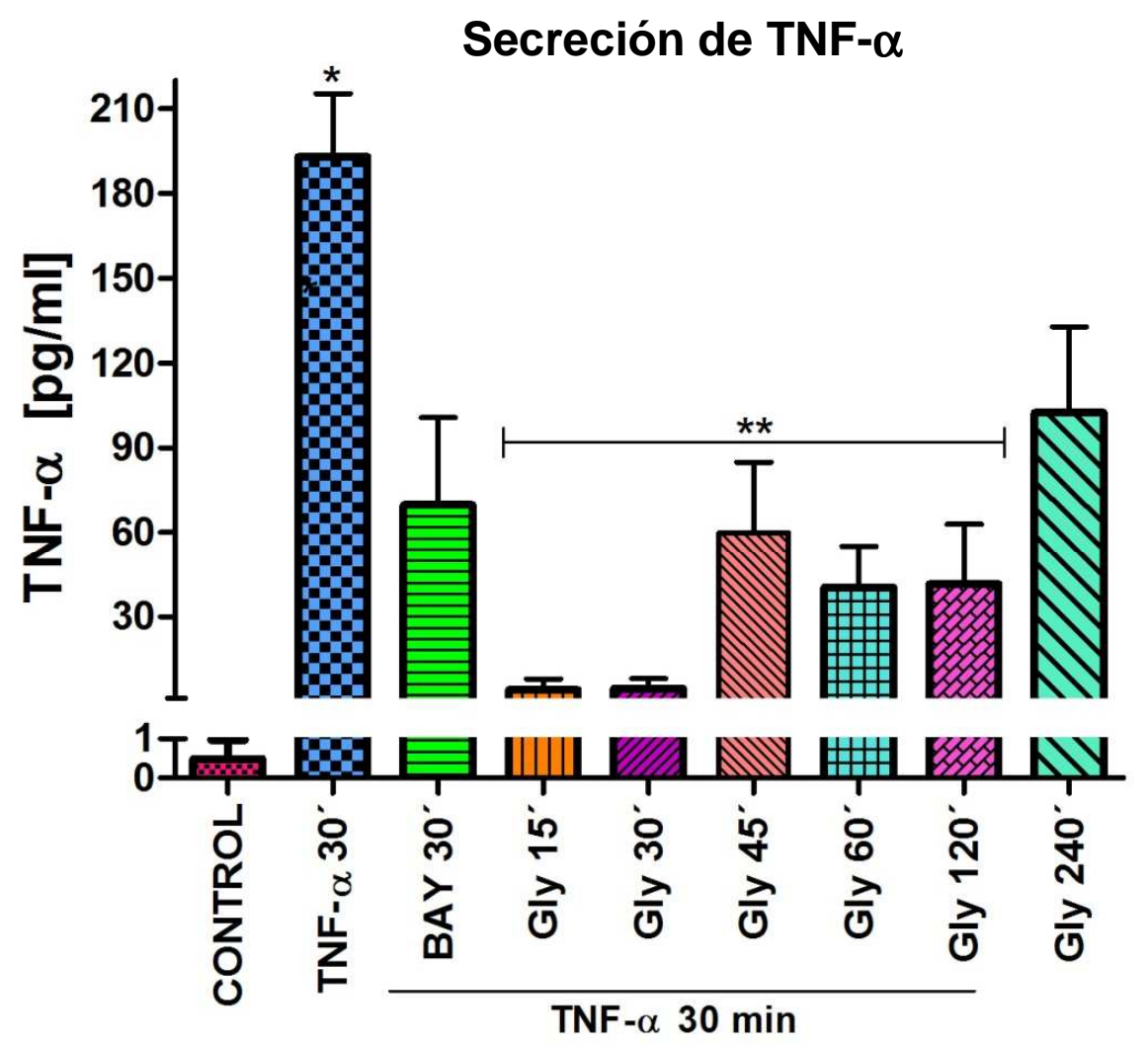

Figura 13. Secreción de TNF- $\alpha$ en los adipocitos pretratados con glicina a $10 \mathrm{mM}$. Cuantificación de la secreción de TNF- $\alpha$ en el sobrenadante del medio de cultivo de Ios adipocitos mediante la prueba de ELISA. El histograma muestra media \pm S.E.M. de una $n=6$. *Significativamente diferente con respecto al control, $p<0.05$, ${ }^{* *}$ Significativamente diferente con respecto al tratamiento con TNF- $\alpha p<0.05$. 


\section{DISCUSIÓN}

La glicina forma parte de la estructura de muchas proteínas, es un aminoácido pequeño y el más simple. Sus propiedades se han atribuido a su tamaño y a la falta de una cadena lateral, la cual puede afectar características físicas como carga, hidrofobicidad o cambios estructurales, que le permiten desempeñar un papel importante en la estructura de proteínas y actuar como un modificador biológico (Serrano y col., 1992). En condiciones normales la concentración sérica de glicina en los seres humanos oscila entre 200-400 $\mu \mathrm{M}$ (Zhong y col., 2003). Los seres humanos han utilizado este aminoácido durante 60 años por sus diversos efectos, generando el estudio de su función y mecanismos de acción; además, con el uso de la glicina no se han observado efectos adversos o tóxicos durante su ingestión en varios modelos experimentales (Khan y col., 2006).

Hay estudios que muestran que la glicina actúa sobre células inflamatorias, por ejemplo macrófagos, para suprimir la activación de factores de transcripción, la formación de radicales libres y citocinas (Yamashina y col., 2001). De igual manera se ha utilizado como un complemento en el tratamiento de la DT2 por que su administración disminuye la glicación de proteínas (Andalibi y col., 1993).

Uno de los objetivos principales del presente trabajo fue estudiar cuál es el nivel o punto de regulación de la glicina sobre la vía de señalización de NF-kB activada por TNF- $\alpha$, así como su asociación con la liberación de citocinas inflamatorias en 
adipocitos. Para esto, primero se determinó la citotoxicidad de la glicina mediante la prueba de MTT para determinar la concentración óptima.

La prueba de MTT utiliza como base la sal de azul de tetrazolio, también llamado MTT o metil-tiazolil-tetrazolio (Mosmann y col., 1983), un ensayo colorimétrico ampliamente utilizado en estudios de citotoxicidad y viabilidad celular. En la prueba, la cantidad de MTT reducido a formazán es directamente proporcional al número de células vivas, por lo que es utilizado como un marcador de viabilidad celular (Stockert y col., 2012). Las reacciones bioquímicas que se llevan a cabo en esta prueba son realizadas por enzimas que actúan como catalizadores biológicos principalmente las deshidrogenasas enzimas encargadas de llevar a cabo la oxido-reducción (Mathews y col., 2002).

Esta prueba nos permitió determinar la concentración de glicina en la que los adipocitos presentaron una viabilidad celular superior al $95 \%$ pero por debajo del $100 \%$ después del tratamiento. De acuerdo con los resultados obtenidos, se encontró que la concentración de 10 mM fue la concentración adecuada para trabajar con los adipocitos ya que no se observaron diferencias significativas con respecto al control (Figura 9). De igual manera se encontró que glicina $20 \mathrm{mM}$ disminuye la viabilidad de los adipocitos en comparación con el control. Estos resultados concuerdan con los resultados obtenidos por Loza-Rodríguez (2002), quien demostró que la glicina genera cambios en la viabilidad celular en células Jurkat, en donde a 
mayor concentración de glicina $(22.7 \mathrm{mM})$ la viabilidad disminuye significativamente con respecto al control.

Por otra parte, teniendo en cuenta que los procesos inflamatorios son regulados por la vía de señalización de TNF- $\alpha$, molécula que desencadena una serie de fosforilaciones que permiten la activación del factor de transcripción NF-кB (Hayden y Ghosh 2004, Schmitz y col., 2004), se decidió estudiar la vía canónica de activación de NF-кB por TNF- $\alpha$, como primera aproximación para elucidar la acción de la glicina sobre el proceso inflamatorio.

Esta vía genera una cascada de señalizaciones en la que se activan proteínas muy importantes y que tienen un papel fundamental en la activación de NF-кB. Las proteínas cinasas IKK forman parte de un complejo constituido por tres proteínas: IKK- $\alpha$, IKK- $\beta$ e IKK- $\gamma$ [también Ilamado modulador esencial de NF-кB (NEMO)]. EI complejo IKK $\alpha$ e IKK $\beta$ catalizan la fosforilación de IKB, mientras que NEMO sólo regula esta actividad y no tiene actividad intrínseca de cinasa (Krappmann y col., 2000).

Los mecanismos exactos por los cuales se activan las IKKs son todavía desconocidos; sin embargo, se conoce que para su activación necesitan estar fosforiladas en dos residuos de serina que se encuentran en el loop de activación (las Ser 177 y 181 para IKK $\beta$, y las Ser 176 y 180 para IKK- $\alpha$ ) (Schomer-Miller y col., 
2006). Hay evidencias que indican que IKK $\beta$ media la activación de NF-KB en respuesta a citocinas proinflamatorias y productos microbianos, pero el papel de la IKK- $\alpha$ en la inflamación es desconocido.

Nuestros resultados revelan que el pretratamiento con glicina a $10 \mathrm{mM}$ seguido de la estimulación con TNF- $\alpha$ durante 30 min aumenta la presencia de IKK- $\alpha$ significativamente a los 30 min, 1 y 2 h; dicho aumento fue mayor (28\% más) al producido por TNF- $\alpha$ (Figura 10). Sin embargo, este efecto fue revertido a las $4 \mathrm{~h}$. Por lo tanto, la glicina parece que está interfiriendo en la actividad de IKK- $\alpha$ ya que se observó una mayor presencia en su forma inactiva evitando que esta sea fosforilada y que por consecuencia este generando la disminución en la activación de NF-kB, lo cual podría estar mejorando el perfil inflamatorio.

Esta cascada de señalización se encuentra ampliamente regulada. Se ha demostrado que la activación del factor NF-kB no sólo modula la respuesta inmune sino que también está implicada en la regulación de diversos procesos celulares, como inflamación, adhesión, proliferación, diferenciación, apoptosis y oncogénesis (Karin y Lin, 2002). Por lo tanto, el bloqueo de su activación podría regular la expresión de una gran variedad de genes en respuesta a citocinas proinflamatorias y especies reactivas de oxigeno. De igual manera su activación puede estar regulada por diferentes moléculas. 
Se sabe que los heterodímero p50 y p65 están íntimamente involucrados en la activación de genes proinflamatorios inducidos por IL-1 o TNF- $\alpha$ en monocitos humanos. Hasta ahora sabemos que el heterodímero P50-P65 es activado por glicina y que la vía por la que se suprime la activación de NF-kB es por la vía canónica de TNF- $\alpha$, la cual genera una disminución en la respuesta inflamatoria (Blancas-Flores y col., 2012).

En los resultados obtenidos se observó que, los pretratamientos con glicina 10 $\mathrm{mM}$ y estimulados posteriormente con TNF- $\alpha(5 \mathrm{ng} / \mathrm{ml})$ por $30 \mathrm{~min}$ disminuyen significativamente el nivel de activación de NF-kB a los 30 min y a $1 \mathrm{~h}$, en comparación con TNF- $\alpha$, además se observó que a 1 h tuvo una mayor disminución de la activación de NF-kB hasta un 52\%. Sin embargo, a las 2 h se genera un efecto contrario ya que aumenta significativamente la activación de NF- $\kappa B$ hasta un $65 \%$ con respecto a TNF- $\alpha$ (Figura 11b). Estos resultados concuerdan con los obtenidos por Blancas-Flores (2012), en el que se demostró que el pretratamiento con glicina (10 mM y estimulados con TNF- $\alpha 5 \mathrm{ng} / \mathrm{ml}$ durante $30 \mathrm{~min}$ ) 1 h disminuye la activación de NF-kB en un $32 \%$ y $50 \%$, respectivamente, pero a las 2 h este efecto se revierte.

Se considera que el pretratamiento con glicina tuvo un efecto transitorio con respecto a TNF- $\alpha$ ya que hay una menor o mayor activación de NF- $\kappa B$ a diferentes tiempos mostrando un efecto fluctuante. Estos resultados son indicativos de la forma en la que la glicina puede estar actuando como regulador de la activación de NF-кB. 
Así mismo, se ha reportado que glicina y otros amino ácidos pueden interferir con la activación de NF-kB mediado por TNF- $\alpha$ (Haseagawa y col., 2011; Hasegawa y col., 2012).

De acuerdo con lo anterior, la glicina suprime la activación de NF-кB por estímulo de TNF- $\alpha$, lo que podría estar disminuyendo el estado inflamatorio en los adipocitos. En estudios previos nuestro grupo demostró, tanto en un modelo animal de obesidad como en adipocitos 3T3-L1, que el tratamiento con glicina reduce la expresión de citocinas proinflamatorias, como TNF- $\alpha$, IL6 y resistina, mientras que aumenta la expresión de adiponectina, una citocina antiinflamatoria, y de su regulador PPAR- $\gamma$, haciendo que mejore el perfil inflamatorio, tanto en animales como en cultivos celulares (Alarcon-Aguilar y col., 2008; Garcia-Macedo y col., 2008)

En relación con la leptina, ésta es una hormona que comparte algunas similitudes estructurales con las citocinas; principalmente es secretada por los adipocitos y su síntesis puede ser estimulada por TNF- $\alpha$ o algunos otros factores (Prins, 2002). La regulación de su expresión depende de los depósitos grasos del organismo, por lo que los adipocitos de mayor tamaño producen más leptina. Su secreción se encuentra asociada con la concentración plasmática de insulina, lo cual se debe a que la insulina estimula la expresión de leptina en adipocitos aislados y por lo tanto se ve elevado su nivel circulante. Su secreción genera señales en el sistema nervioso central para la reservas de energía en el tejido adiposo. Las evidencias que 
apuntan a una posible participación de la leptina como adipocina proinflamatoria cada vez son mayores (Lago y col., 2007; Otero y col., 2005; Tilg y Moschen., 2006). $\mathrm{Si}$ bien es cierto que las concentraciones circulantes de leptina aumentan ante estímulos proinflamatorios como TNF- $\alpha$, IL-1, IL-6 o lipopolisacárido, también se ha sugerido que esta elevación podría tener una función protectora (Lago y col., 2007).

Al parecer, los resultados obtenidos muestran que en el control la secreción de leptina se encuentra por arriba de los $140 \mathrm{pg} / \mathrm{ml}$, ya que se sabe que las concentraciones elevadas de insulina estimulan una mayor expresión de leptina (Fawcett y col., 2000). Sin embargo, el tratamiento con TNF- $\alpha(5 \mathrm{ng} / \mathrm{ml})$ por $30 \mathrm{~min}$ disminuyo significativamente la secreción de leptina por debajo de $50 \mathrm{pg} / \mathrm{ml}$, estos resultados concuerdan con los obtenidos por Fawcett y col. (2000) ya que este efecto se atribuye a una disminución en la expresión del gen $o b$ y a que el TNF- $\alpha$ disminuye la actividad de la lipoproteinlipasa y estimula la lipólisis generando una acumulación de lípidos y por esto reducir la secreción de leptina en adipocitos. Pero también TNF- $\alpha$ suprime la expresión del factor de transcripción C/EBPa necesario para la transcripción del gen ob y de la expresión de PPAR (regulador directo de adipogénesis) y la promoción de de sensibilidad a la insulina mecanismo por el cual se podría estar alterando la secreción de leptina (Chen y col., 2000; Rosen y col., 2002). Así mismo se observó que después de $1 \mathrm{~h}$ y $4 \mathrm{~h}$ del pretratamiento con glicina regresa a concentraciones basales parecidas al control, en comparación con TNF- $\alpha$ 
aumenta la secreción de leptina efecto que podría estar generando protección al adipocito.

El TNF- $\alpha$ juega un papel importante en este trabajo ya que actúa como un

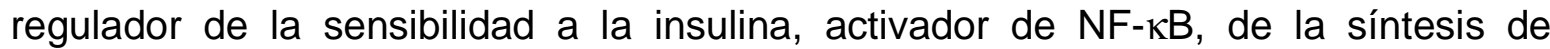
diferentes citocinas inflamatorias y de su auto-regulación sintetizando más TNF- $\alpha$. Su expresión se encuentra aumentada en el tejido adiposo de ratones y humanos con obesidad y, de hecho, constituyó el primer hallazgo que relacionaba la obesidad con la inflamación sistémica (Hotamisligil, 2006), por lo que se considera como marcador inflamatorio asociado con adiposidad.

En los resultados obtenidos se observó que el pretratamiento con glicina a 15, 30, 45 min, 1 y 2 h disminuye significativamente la secreción de TNF- $\alpha$ con respecto al control positivo (TNF- $\alpha$ ), datos que coinciden con los trabajos realizados por nuestro grupo en los que se aprecio una disminución en los niveles de expresión del RNAm en célula 3T3-L1, al igual, que en el tejido adiposo (Alarcon-Aguilar y col., 2008; Almanza-Perez y col., 2010; Garcia-Macedo y col., 2008).

Sin embargo, a las $4 \mathrm{~h}$ del pretratamiento con glicina se observó un efecto contrario, ya que aumentó la secreción de TNF- $\alpha$ con respecto a los otros tiempos ya mencionados; a pesar del efecto observado, los resultados muestran que esta elevación en la secreción de TNF- $\alpha$ no genera una mayor activación de NF-кB. 
Los resultados obtenidos hasta ahora nos indican que la acción de glicina actúa sobre la vía canoníca de TNF- $\alpha$ para la activación de NF- $\kappa B$, en la cual modifica la actividad de IKK- $\alpha$ inhibiendo la activación de NF-KB y regulando la expresión y secreción de citocinas proinflamatorias como TNF- $\alpha$ y leptina (Figura 14). Estos resultados apoyan la idea de que la glicina podría estar regulando el proceso inflamatorio crónico característico de la obesidad a través de un mecanismo que involucra la participación de estos mediadores.

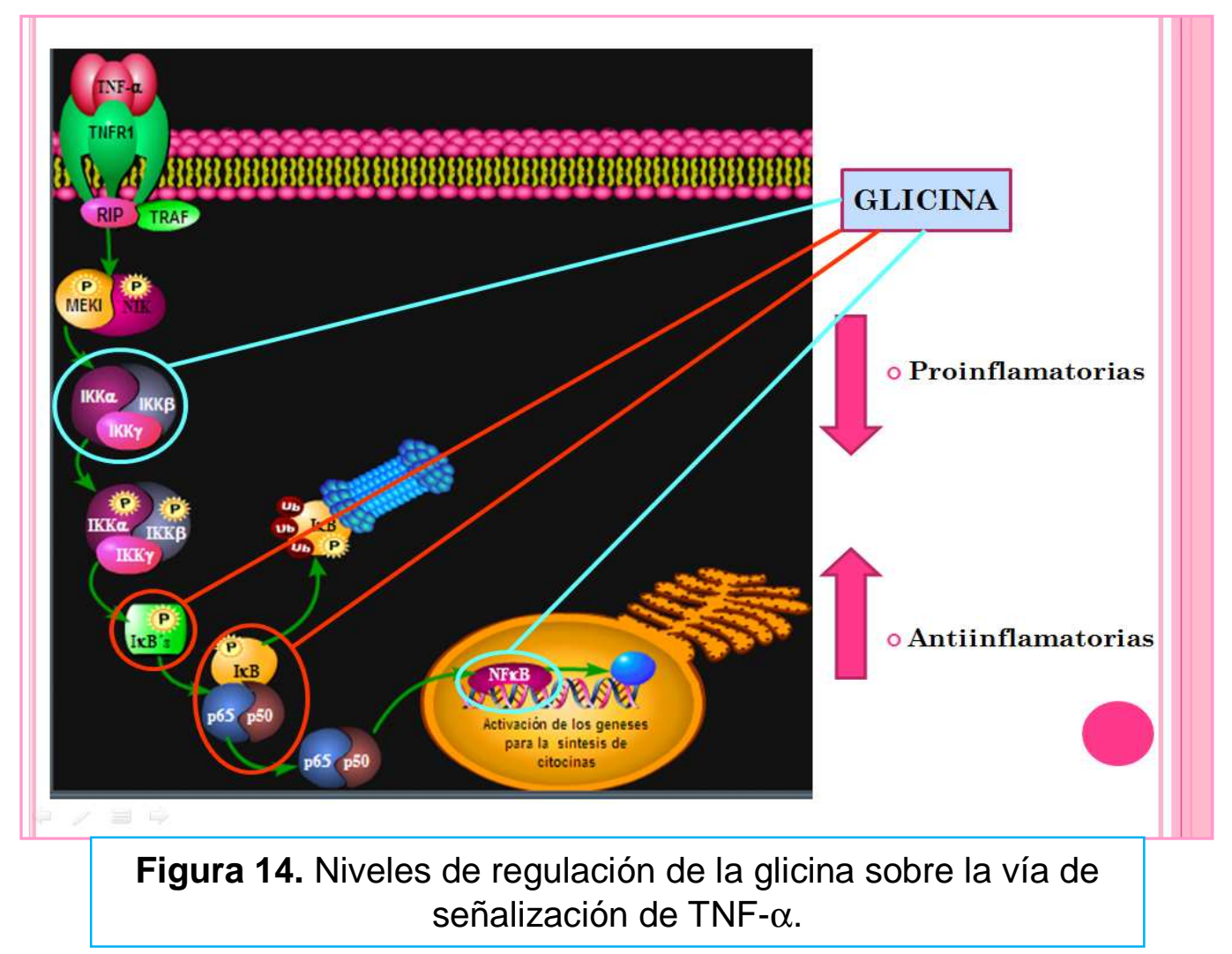




\section{CONCLUSIONES}

1. La presencia de IKK- $\alpha$ está regulada por la acción de glicina.

2. La glicina tiene un efecto transitorio, generando que a diferentes tiempos se eleve o disminuya la activación de NF- $\kappa \mathrm{B}$.

3. El pretratamiento de glicina por 15 min y hasta 2 h disminuye la secreción de TNF- $\alpha$. No obstante a las 4 h se observa un efecto contrario ya que aumenta la secreción de TNF- $\alpha$ como un efecto secundario, pero que no genera una mayor activación de NF-кB.

4. El estimulo con TNF- $\alpha$ (control positivo) disminuye la secreción de leptina. Sin embargo el pretratamiento con glicina (10mM seguidos de un pulso de TNF- $\alpha$ $5 \mathrm{ng} / \mathrm{ml})$ a 15, 30, 45 min, 1 y 2 h no modifico la secreción de leptina, pero a $1 \mathrm{~h}$ y 4h se eleva significativamente su secreción hasta llegar a concentraciones basales parecidas al control.

5. Estos datos nos permiten avanzar en el mecanismo de acción de la glicina para explicar la disminución en la síntesis de citocinas proinflamatorias (TNF- $\alpha$ ) y mejorar el perfil inflamatorio, así como su regulación sobre la activación de NF-kB en adipocitos. 


\section{PERSPECTIVAS}

i) Cuantificar el grado de fosforilación del complejo IKK (IKK- $\alpha$, IKK- $\beta$ e IKK- $\gamma$ ).

ii) Evaluar la participación del proteosoma durante el tratamiento con glicina.

iii) Determinar si la glicina es capaz de intervenir en la activación de otros factores de transcripción como la proteína activadora 1 (AP1) o las proteínas STAT blancos importantes en la respuesta inflamatoria.

iv) Establecer si la glicina puede estar regulando otras vías de señalización relacionadas con la inflamación como la vía asociada a receptores tipo toll o la regulada por interleucinas como IL-1.

v) Determinar si los fibroblastos diferenciados a adipocitos tienen en su membrana receptores para glicina con el fin de explicar si la glicina ejerce su efecto a través de estos y si se encuentran asociados a canales de $\mathrm{Cl}^{-}$. 


\section{BIBLIOGRAFÍA}

Ahima RS.(2006). Adipose tissue as an endocrine organ. Obesity:14; 242S-2429S.

Alarcon-Aguilar FJ., Almanza-Perez JC., Blancas G., Angeles S., Garcia-Macedo R., Roman R., Cruz M. (2008). Glycine regulates the production of pro-inflammatory cytokines in lean and monosodium glutamate-obese mice. Eur $\mathrm{J}$ Pharmacol; 599:152-158.

Almanza-Perez JC, Alarcon-Aguilar FJ, Blancas-Flores G, Campos-Sepulveda AE, Roman-Ramos R, Garcia-Macedo R, Cruz M. (2010). Glycine regulates inflammatory markers modifying the energetic balance through PPAR and UCP-2. Biomed Pharmacother. ; 64(8):534-40.

Andalibi A., Liao F., Imes S., Fogelman AM., Lusis AJ. (1993). Oxidized lipoproteins influence gene expression by causing oxidative stress and activating the transcription factor NF-kappa B. Biochem. Soc. Trans; 3: 651-655.

Bours V., Bonizzi G., Bentires-Alj M., Bureau F., Piette J., Lekeux P., Merville M. (2000). NF-kappaB activation in response to toxical and therapeutical agents: role in inflammation and cancer treatment. Toxicol; 153(1-3): 27-38. 
Bui NT., Livolsi A., Peyron JF., Prehn JH. (2001). Activation of nuclear factor kappaB and $B c l-x$ survival gene expression by nerve growth factor requires tyrosine phosphorylation of IkappaBalpha. J Cell Biol; 152(4):753-764.

Bloomgarden Z. (2003). The Endocrine Society Meeting: Topics in insulin sensitivity and hypertension: diabetes Care; 26: 2679-2668.

Blancas-Flores G., Alarcon-Aguilar FJ., Garcia-Macedo R., Almanza-Perez JC., Flores-Sáenz J.L., Roman R., Ventura-Gallegos J.L., Kumate J., Zentella-Dehesa a., Cruz M. (2012). Glycine seppresses TNF-alpha-induced activation of NF-kB in differentiated 3T3-L1 adipocytes. Eur J Pharmacol; 689: 270-277.

Bremner P., Heinrich M. (2002). Natural products as modulators of the NF-kBpathway. J. Pharm. Pharmacol. 54: 453-472.

Brun-Buisson C. (2000). The epidemiology of the systemic inflammatory response. Intensive Care Med; 26(Suppl1): S64-S74.

Cinti S. (2001). The adipose organ: morphological perspectives of adipose tissues. Proc. Nutr. Soc; 60: 319-328. 
Cruz M, Maldonado B., Mondragon G., Sánchez B., Wacher N., Carvajal S., Kumate J. (2008). Glycine treatment drecreases proinflammatory cytokines and increases interferon- $\gamma$ in patients with type 2 diabetes. J Endocrinol Invest; 31: 69499.

Chen, S.S., Chen, J.F., Johnson, P.F., Muppala, V., and Lee, Y.H. (2000). C/EBP, when expressed from the C/EBP gene locus, can functionally replace C/EBP in liver but not in adipose tissue. Mol. Cell. Biol. 20: 7292-7299.

Detrick B., Nagineni C N. and Hooks J J. (2008). Cytokines: Regulators of Immune Responses and Key Therapeutic Targets In: M.R.G.O.G.a.A.D. Donnenberg (Ed), Human Immunology, CRC Press, Taylor \& Francis Group, pp. 495-516.

Dinarello, C A. (2000): Proinflammatory cytokines. Chest 118(2): 503-8.

Evan D. Rosen, Chung-Hsin Hsu, Xinzhong Wang, Shuichi Sakai, Mason W. Freeman, Frank J. Gonzalez, and Bruce M. Spiegelman. (2002) C/EBPa induces adipogenesis through PPARy: a unified pathway. Genes Dev; 16(1): 22-26.

Eichacker PQ., Parent C., Kalil A., Esposito C., Cui X., Banks SM., Fitz Y., Danner RL., Natanson C.(2002). Risk and the efficacy of antiinflammatory 
agents: retrospective and confirmatory studies of sepsis. Am J Respir Crit Care Med; 166:1197-205.

Fawcett R, Waechter A, Williams L, Zhang P, Louie R, Jones R, Inman M, Huse J, Considine V. (2000). Tumor necrosis factor-alpha inhibits leptin production in subcutaneous and omental adipocytes from morbidly obese humans. J Clin Endocrinol Metab. ;85(2):530-5.

Friedman JM.(2000). Obesity in the new millennium. Nature; 404: 632-634.

Fruhbeck G., Gomez-Ambrosl J., MuruzabalFJ., Burrell MA. (2001). The adipocyte: a model for integration of endocrine and metabolic signaling in energy metabolism regulation. Am J Physiol Endocrino IMetab; 280: 827-847.

Gallagher D., GutierrezH., Gavalda N., O'Keeffe G., Hay R., Davies AM.(2007). "Nuclear factor-kappaB activation via tyrosine phosphorylation of inhibitor kappa Balpha is crucial for ciliary neurotrophic factor-promoted neurite growth from developing neurons." J Neurosci; 27(36): 9664-9669.

Garcia-Barreno P. (2008). Inflamación. Rev.R.Acad.Cienc.Exact.Fís.Nat. (Esp) Vol. 102, №. 1, pp 91-159. 
Garcia-Macedo R., Sanchez-Muñoz F., Almanza-Perez JC., Duran-Reyes G., Alarcon-Aguilar FJ., Cruz M. (2008). Glycine increases mRNA adiponectin and diminishes pro-inflammatory adipokines expression in 3T3-L1 cells. Eur J Pharmacol; 587:317-321.

González HM., Bastidas RB., Ruiz MB., Godínez S., Panduro A. (2002). Funciones endocrinas de la célula adiposa Rev Edocrinol Nutr; 10:140-146.

Ghosh S., and Karin M.(2002). "Missing pieces in the NF-kappaB puzzle." Cell 109 Suppl; S81-96.

Hasegawa S., Ichiyama T., Sonaka I., Ohsaki A., Hirano R., Haneda Y., Fukano R., Hara M., Furukawa S. (2011). Amino acids exhibit anti-inflammatory effects in human monocytic leukemia cell line, THP-1 cells. Inflamm Res; 60: 1013-1019.

Hasegawa S., Ichiyama T., Sonaka I., Ohsaki A., Okada S., Wakiguchi H., Kudo K., Kittaka S., Hara M., Furukawa S. (2012). Cysteine, histidine and glycine exhibit anti-inflammatory effects in human coronary arterial endothelial cells. Clin Explmmunol; 167: 269-274.

Hayden M., y Ghosh S.(2004)."Signaling to NF-kappaB". Genes Dev; 18(18): 21952224. 
Hayden M., y Ghosh S. (2008). "Shared principles in NF-kappaB signaling." Cell; 132(3): 344-362.

Hirata K., Dichek JA., Cioffi SJ., Leeper L., Quintana GS., Kronmal AD., Cooper T. (2000). Cloning of a unique lipase from endotelial cells extend the lipase gene family. J Biol Chem; 274: 14170-14173.

Hotamisligil GS.(2006). Inflammation and metabolic disorders. Nature; 444: 860-7.

Huynh QK., Boddupalli H., Rouw SA., Koboldt CM., Hall T., Sommers C., Hauser SD., Pierce JL., Combs RG., Reitz BA., Diaz-Collier JA., Weinberg RA., Hood BL., Kilpatrick BF., Tripp CS. (2000). Characterization of the recombinant IKK1/IKK2 heterodimer. Mechanisms regulating kinase activity. J. Biol. Chem; 275:25883-25891.

HäckerH., and Karin M. (2006). "Regulation and function of IKK and IKK-related kinases."Sci STKE; (357): Pre13.

Karin M., and Lin A. (2002). "NF-kappaB at the crossroads of life and death." Nat Immunol; 3(3): 221-227.

Kershaw EE., and Filer JS.(2004). Adipose tissue as an endocrine organ. J Clin Endocrinol Metab; 89:2548-2556. 
Kopelman PG. (2000). Obesity as a medical problem. Nature; 404:635-643.

Khan M., Van Der Wieken LR., Riezebos RK., Tijssen JG., Kiemeneij F., Slagboom T., Laarman GJ.(2006). Oral administration of glycine in the prevention of restenosis after coronary angioplasty. A double blind placebo controlled randomized feasibility trial evaluating safety and efficacy of glycine in the prevention of restenosis after angioplasty. Acute Cardiac Care; 8:58-64.

Krappmann D., Hatada EN., Tegethoff S., Li J., Klippel A., Giese K., Baeuerle PA., Scheidereit C. (2000). The I kappa B kinase (IKK) complex is tripartite and contains IKK gamma but not IKAP as a regular component.J Biol Chem; 275:29779_ 29787.

Lau DCW., Dhillon B., Yan H., Szmitko PE., Verma S. (2005). Adipokines: molecular links between obesity and atherosclerosis. Am J Physiol Heart CircPhysiol; 288: H2031-41.

Lago F., Diéguez C., Gómez-Reino J., Gualillo O. (2007). Adipokines as emerging mediators of immune response and inflammation. Nat Clin Pract Rheumatol; 3: 71624. 
Lin Y., Berg A., Lyengar P., Lam T., Giacca A., Combs T., Rajala M., Du X., Rollman B., Li W., Hawkins M., Barzilai N., Rhodes c., Fantus G., Brownlee M., Sherer P. (2005). The hyperglycemia-induce inflammatory response in adipocytes. J Biol Chem; 208: 4617-4625.

Loza H., Torres N., Díaz M., Cruz, M., Hernández D. (2007). Glycine reduces the oxidative stress in patients with Metabolic Syndrome. FASEB J; 21: 185.

Loza-Rodríguez Hilda. (2010). Influencia de la glicina y de un extracto de Hibiscussabdariffa sobre la expresión los genes de las enzimas antioxidantes en células Jurkat. Maestria en Biología Experimental, UAM-Iztapalapa.

Matilla B., Mauriz JL., Culebras JM., González-Gallego J y González P. (2002). La glicina: un nutriente antioxidante protector celular. Nutrición Hospitalaria; 17:2-9.

Mathews CK., Van Holde KE., Ahern KG. (2002) Bioquímica. 3a Ed. Editorial PEARSON EDUCACIÓN, S. A., Madrid; pp: 544.

May MJ., D’Acquisto F., Madge LA., Glockner J., Pober JS., Ghosh S. (2000). Selective inhibition of NF-K B activation by a peptide that blocks the interaction of NEMO with the IK B kinase complex. Science; 289(5484): 1550-1554. 
Medzhitov R. (2008) Origin and physiological roles of inflammation. Nature 454: 428-35.

Mémet S. (2006). "NF-kappaB functions in the nervous system: from development to disease". Biochem Pharmacol; 72(9): 1180-1195.

Mosmann T. (1983). Rapid colorimetric assay for cellular growth and survival: Application to proliferation and cytotoxicity assay. J. Inmunol. Methods; 65: 55-63.

Nicoletti G., Giugliano G., Pontillo A., Cioffi M., D’Andrea F., Giugliano D., Esposito K. (2003). Effect of a multidisciplinary program of weight reduction on endothelial function in obese women. J Endocrinol Invest; 26(3): RC5-8.

Nishimura S., Manabe I., Nagasaki M., Seo K., Yamashita H., Hosoya Y., Ohsugi M., Tobe K., Kadowaki T., Nagai R., Sugiura S. (2008). In vivo imaging in mice reveals local cell dynamics and inflammation in obese adipose tissue. J Clin Invest; 118(2): 710-21.

Opal S M., y DePalo VA. (2000): Anti-inflammatory cytokines. Chest 117(4): 116272. 
Otero M., Lago R., Lago F., Casanueva FF., Diéguez C., Gómez-Reino JJ., Gualillo O. (2005). Leptin, from fat to inflammation: old questions and new insights. FEBS Lett; 17; 579(2): 295-301.

Perkins N. (2006). "Post-translational modifications regulating the activity and function of the nuclear factor kappa B pathway".Oncogene; 25(51): 6717-6730.

Prins JB.(2002). Adipose tissue as an endocrine organ. Best Prac Res Clin Endocrinol Metab; 16: 639-651.

Recasens M., Ricart W., Fernandez-Real JM.(2004). Obesidad e inflamación. Rev Med Univ Navarra; 48:49-54.

Ronti T., Lupattelli G., Mannarino E. (2006). The endocrine function of adipose tissue: an update. Cliln Endocrinol; 64:355-365.

Serrano L., Neira J., Sancho J. (1992). Effect of alanine versus glycine in a-helices on protein stability. Nature; 356: 453-55.

Surmi BK., Hasty AH. (2008) Macrophage infiltration into adipose tissue: initiation, propagation and remodeling. Future Lipidol; 3: 545-56. 
Sbarbati A., Osculati F., Silvani D., Benati, D; GalièM., Camoglio FS., Rigotti G., Maffeis C. (2006). Obesidad e inflamación: pruebas de una lesión elemental. Pediatrics (edEsp); 61(1):33-36.

Schmitz ML.,Mattioli I., Buss H.,Kracht M. (2004). NF-kappaB: a multifaceted transcription factor regulated at several levels. Chembiochem: A European Journal of Chemical Biology; 5:1348-1358.

Schomer-Miller B.,Higashimoto T.,Lee YK., Zandi E.(2006). "Regulation of IkappaB kinase (IKK) complex by IKKgamma-dependent phosphorylation of the Tloop and C terminus of IKKbeta". J BiolChem; 281(22): 15268-15276.

Scotto d'Abusco, A., Politi L., Giordano C., Scandurra R.(2010). "A peptidylglucosamine derivative affects IKKalpha kinase activity in human chondrocytes". Arthritis Res Ther; 12(1): R18.

Shoelson SE., Herrero L., Naaz A. (2007). Obesity, inflammation, and insulin resistance. Gastroenterology; 132: 2169-80.

Spittler A., Reissner CM., Oehler R., Gornikiewicz A., Gruenberger T., Manhart N., Brodowicz T., Mittlboeck M., Boltz-Nitulescu G., Roth E. (1999). 
Immunomodulatory effects of glycine on LPS-treated monocytes: reduced TNF- $\alpha$ production and accelerated IL-10 expression. FASEB J; 13:563-571.

Steppan CM., Brown EJ., Wright CM., Bhat S., Banerjee RR., Dai CY., Enders GH., Silberg DG., Wen X., Wu GD., and Lazar MA.(2001). A family of tissue-specific resistin-like molecules. Proc. Natl. Acad. Sci. U. S. A.; 98: 502-506.

Stockert JC., Blázquez-Castro A., Cañete M., Horobin RW., Villanueva A.(2012). MTT assay for cell viability: Intracellular localization of the formazan product is in lipid droplets. Acta Histochem. Doi:10.1016/j.acthis.2012.01.006.

Takada Y., Mukhopadhyay A.,Kundu GC., Mahabeleshwar GH., Singh S., AggarwalBB. (2003). "Hydrogen peroxide activates NF-kappa B through tyrosine phosphorylation of I kappa B alpha and serine phosphorylation of p65: evidence for the involvement of I kappa B alpha kinase and Sykproteintyrosine kinase". J BiolChem; 278(26): 24233-24241.

Tilg H., Moschen AR. (2006). Adipocytokines: mediators linking adipose tissue, inflammation and immunity. Nat Rev Immunol; 6: 772-83. 
Vainio H, Bianchini F. (2002). IARC International Agency for Cancer handbook of cancer preventionWeight control and physical activity. Lyon, France: IARC Press, vol 6.

Van Leiden HA., Dekker JM., Moll AC., Nijpels G., Heine RJ., Bouter LM.,Stehouwer CD., Polak BC.(2002). Blood pressure, lipids, and obesity are associated with retinopathy: the Hoorn study. Diabetes Care; 25(8): 1320-5.

Vega R. (2010). El adipocito y la respuesta inmune. Rev Fac Med UNAM; Vol. 53 No. 1.

Weisberg SP., McCann D., Deasi M., Rosenbaum M., LeibelRL.,Ferrante AW. (2003). Obesity is associated with macrophage accumulation in adipose tissue. J Clin Invest; 112(12): 1796-1808.

Weiss U. (2002). Nature insight: Inflammation. Nature 420: 845.

Wellen KE., y Hotamisligil GS.(2003). Obesity-induced inflammatory changes in adipose tissue. J Clin Invest; 112:1785-1788.

Yamagishi S., Nakamura K., Jinnouchi Y., Takenaka K., Imaizumi T. (2005). Molecular mechanisms for vascular injury in metabolic syndrome. Drugs Exp Clin Res; 31(3): 123-9. 
Yamashina S., Konno A., Wheeler M. (2001). Endothelial cells contain a glycinegated chloride channel. Nutr Cancer; 40: 197-204.

Zechner R., Strauss J., Frank S., Wagner E., Hoffman W., Kratky D., Hiden M., Levak-Frank S. (2000). The role of lipoprotein lipase in adipose tissue development and metabolism. Int J Obes; 24:S53-S56.b.

Zhong Z., Wheeler D., Xiangli F., Schemmer P., Yin M., Bunzendaul H., Bradford B., Lemasters J. (2003) L-Glycine: a novel antiinflammatory, immunomodulatory, and cytoprotective agent. Clin. Nutr. \&Metab. Care; 6: 229-240. 